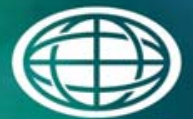

Savannah River

National Laboratory "m

OPERATED BY SAVANNAH RIVER NUCLEAR SOLUTIONS

\title{
Destruction of Oxalate in HB-Line using Sodium Permanganate
}

R. A. Pierce and C. A. Nash

May 2014

SRNL-ST1-2014-00213, Revision 0 


\section{DISCLAIMER}

This work was prepared under an agreement with and funded by the U.S. Government. Neither the U.S. Government or its employees, nor any of its contractors, subcontractors or their employees, makes any express or implied:

1. warranty or assumes any legal liability for the accuracy, completeness, or for the use or results of such use of any information, product, or process disclosed; or

2. representation that such use or results of such use would not infringe privately owned rights; or

3. endorsement or recommendation of any specifically identified commercial product, process, or service.

Any views and opinions of authors expressed in this work do not necessarily state or reflect those of the United States Government, or its contractors, or subcontractors.

\section{Printed in the United States of America \\ Prepared for U.S. Department of Energy}


Keywords: HB-Line, oxalate, permanganate

Retention: Permanent

\section{Destruction of Oxalate in HB-Line using Sodium Permanganate}

R. A. Pierce and C. A. Nash

May 2014

Prepared for the U.S. Department of Energy under 


\section{REVIEWS AND APPROVALS}

\section{AUTHORS:}

R. A. Pierce, Separation \& Actinide Science Programs

Date

C. A. Nash, Advanced Characterization and Processing Technology

Date

TECHNICAL REVIEW:

M. L. Crowder, Separation \& Actinide Science Programs

Date

S. L. Garrison, H-Canyon Outside Fac \& Tech Support

Date

APPROVAL:

T. B. Brown, Manager

Date

Separation \& Actinide Science Programs

S. L. Marra, Manager

Date

Environmental \& Chemical Process Technology Research Programs

J. E. Therrell, Manager

Date

HB-Line Engineering 


\section{EXECUTIVE SUMMARY}

During HB-Line $\mathrm{Pu}-239$ operations, plutonium $(\mathrm{Pu})$ is precipitated as $\mathrm{Pu}(\mathrm{IV})$ oxalate $\left[\mathrm{Pu}\left(\mathrm{C}_{2} \mathrm{O}_{4}\right)_{2}\right]$ using oxalic acid $\left(\mathrm{H}_{2} \mathrm{C}_{2} \mathrm{O}_{4}\right)$. Following the removal of precipitate by filtration, the $\mathrm{H}_{2} \mathrm{C}_{2} \mathrm{O}_{4}$ must be removed from solution before the filtrate can be discharged to $\mathrm{H}$-Canyon under one criticality-control strategy. HB-Line uses sodium permanganate $\left(\mathrm{NaMnO}_{4}\right)$ solution to oxidize $\mathrm{H}_{2} \mathrm{C}_{2} \mathrm{O}_{4}$ to carbon dioxide $\left(\mathrm{CO}_{2}\right)$ and water. Excess $\mathrm{NaMnO}_{4}$, which reacts to form manganese dioxide $\left(\mathrm{MnO}_{2}\right)$ solids, is converted to soluble manganese via a reaction with sodium nitrite $\left(\mathrm{NaNO}_{2}\right)$. HB-Line Engineering requested the Savannah River National Laboratory (SRNL) to verify the quantities and addition rates of $\mathrm{NaMnO}_{4}$ and $\mathrm{NaNO}_{2}$ required to react excess oxalic acid and $\mathrm{MnO}_{2}$ solids without over-pressurization of the reaction vessel.

According to the literature, the oxidation of $\mathrm{H}_{2} \mathrm{C}_{2} \mathrm{O}_{4}$ by permanganate involves three concurrent chemical reactions. The net effect of the three reactions is that there is an observed incubation period at the outset of the process chemistry. However, as the reaction progresses, the reaction rate accelerates until the end point is reached. The end point is visibly identified by the formation of brown $\mathrm{MnO}_{2}$ solids.

Four titration experiments at 1.0-6.0 $\mathrm{M} \mathrm{HNO}_{3}$ confirmed that the $\mathrm{H}_{2} \mathrm{C}_{2} \mathrm{O}_{4}$ oxidation reaction proceeds by both the kinetics and stoichiometry reported in the literature. The data show that as $\mathrm{NaMnO}_{4}$ is added the $\mathrm{Na}$ and $\mathrm{Mn}$ concentrations increased while the $\mathrm{H}_{2} \mathrm{C}_{2} \mathrm{O}_{4}$ concentration decreased. However, once the $\mathrm{H}_{2} \mathrm{C}_{2} \mathrm{O}_{4}$ was below detectable limits, the addition of $\mathrm{NaMnO}_{4}$ caused the soluble $\mathrm{Mn}$ concentration to decrease (from the formation of $\mathrm{MnO}_{2}$ solids) while the Na concentration continued to increase.

Process flowsheet testing confirmed that the reaction behavior and chemical ratios demonstrated during oxalate titration testing are applicable during conditions of continuous $\mathrm{NaMnO}_{4}$ feeding. In seven experiments ranging from $1.4 \mathrm{M}$ to $7.0 \mathrm{M} \mathrm{HNO}_{3}$, the system behavior was consistent with the reactions described in the literature.

Gas samples collected from four experiments showed less-than-detectable concentrations of $\mathrm{H}_{2}$ gas. In each test, the gas contained air diluted with $\mathrm{CO}_{2}$ released from the oxidation of $\mathrm{H}_{2} \mathrm{C}_{2} \mathrm{O}_{4}$. Using baseline flowsheet feed rates for $\mathrm{NaMnO}_{4}$, the maximum gas generation rate per liter of reaction solution was consistently $750-800 \mathrm{~mL} / \mathrm{min}$, and was not a function of $\mathrm{HNO}_{3}$ concentration. The quantity of gas collected was $94-95 \%$ of the theoretical value.

After the oxidation of $\mathrm{H}_{2} \mathrm{C}_{2} \mathrm{O}_{4}$ is complete, the addition of excess $\mathrm{NaMnO}_{4}$ yields $\mathrm{MnO}_{2}$ solids. The filtrate must be free of solids prior to being discharged to $\mathrm{H}$-Canyon. Therefore, the $\mathrm{MnO}_{2}$ solids are dissolved through the addition of $\mathrm{NaNO}_{2}$ solution. Experimentation confirmed that the quantity of $\mathrm{NaNO}_{2}$ required to dissolve $\mathrm{MnO}_{2}$ solids can be accurately calculated from the amount of excess $\mathrm{NaMnO}_{4}$ added (present as $\mathrm{MnO}_{2}$ solids). Experimental data show good agreement between theoretical and actual $\mathrm{NaNO}_{2}$ addition quantities.

Periodically, the precipitator tanks will be cleaned of residual $\mathrm{Pu}\left(\mathrm{C}_{2} \mathrm{O}_{4}\right)_{2}$ using $14 \mathrm{M} \mathrm{HNO}_{3}$. The oxalate associated with the $\mathrm{Pu}\left(\mathrm{C}_{2} \mathrm{O}_{4}\right)_{2}$ solids will also be oxidized with $\mathrm{NaMnO}_{4}$. Using cerium as a surrogate for $\mathrm{Pu}$, the reactions described in the literature govern the oxidation of oxalate at 1.4-7.0 $\mathrm{M} \mathrm{HNO}_{3}$. At 10-14 $\mathrm{M} \mathrm{HNO}_{3}$, reactions with cerium result in consumption of higher quantities of $\mathrm{NaMnO}_{4}$ when compared to the tests at 1.4-7.0 M. Based on data in the literature, the potential exists for similar highacid reactions when processing $\mathrm{Pu}$. Therefore, precipitator clean-out solution should be diluted to 1.4-7 $\mathrm{M} \mathrm{HNO}_{3}$ prior to the addition of $\mathrm{NaMnO}_{4}$.

Quantities and flow rates of $\mathrm{NaMnO}_{4}$ and $\mathrm{NaNO}_{2}$ rates have been recommended for the baseline process flowsheet and the precipitator clean-out operation. A sampling strategy has also been proposed. 


\section{TABLE OF CONTENTS}

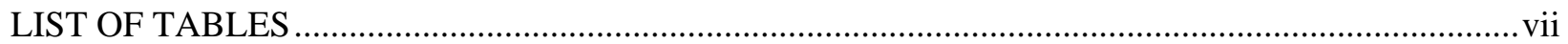

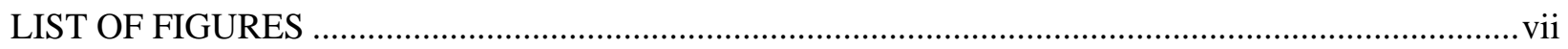

LIST OF ABBREVIATIONS .........................................................................................................

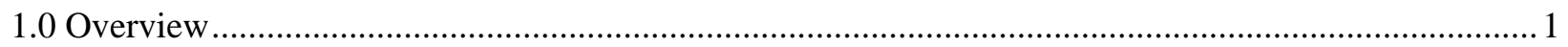

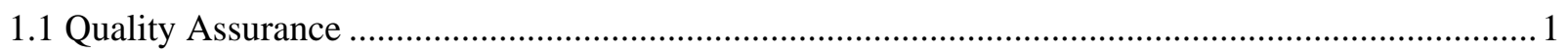

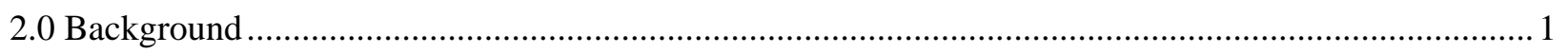

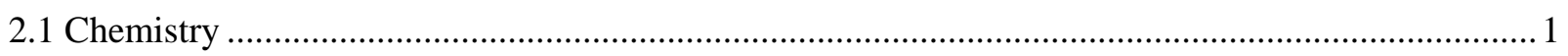

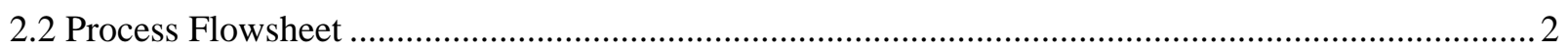

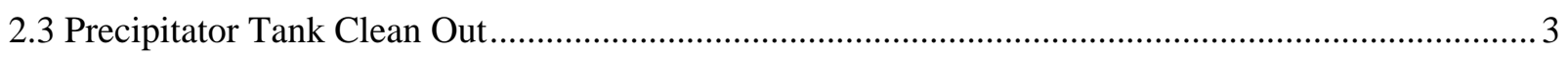

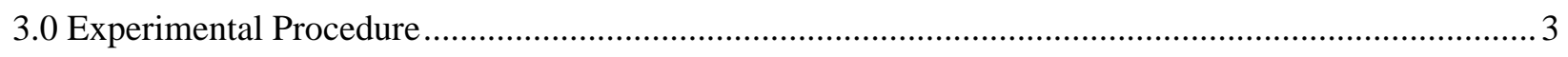

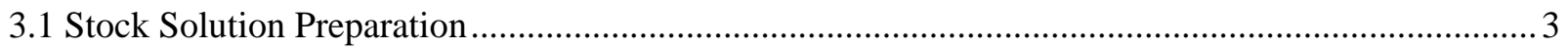

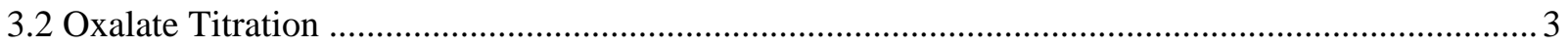

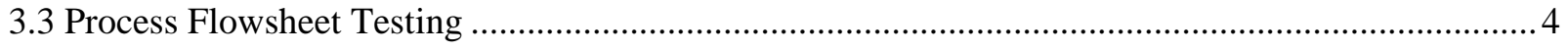

3.4 Precipitator Tank Clean-Out Solution ........................................................................................... 7

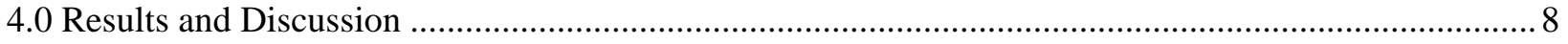

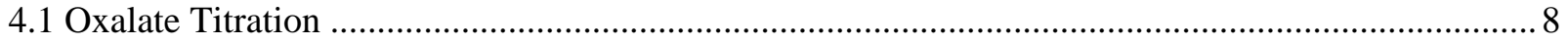

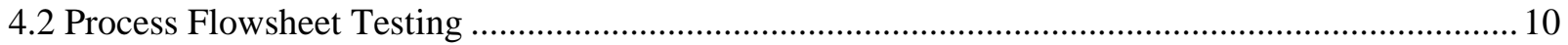

4.2.1 Oxalate Destruction Solution Analyses ……............................................................................. 11

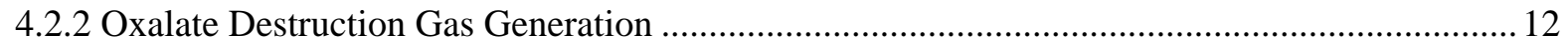

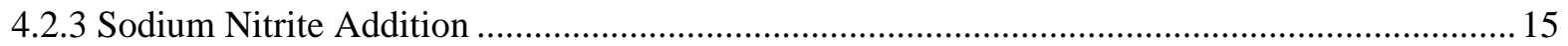

4.3 Precipitator Tank Clean-Out Solution ........................................................................................ 17

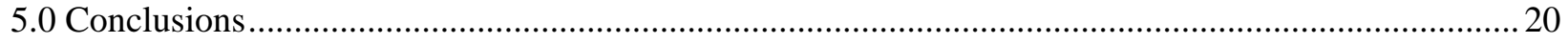

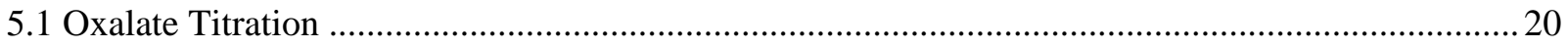

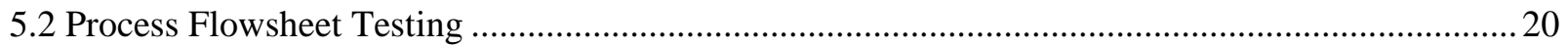

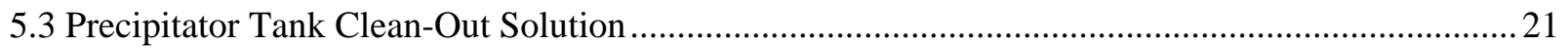

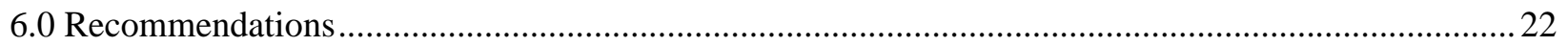

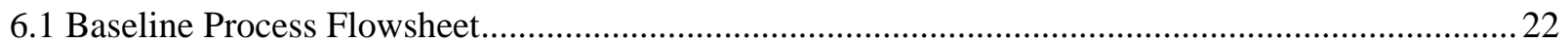

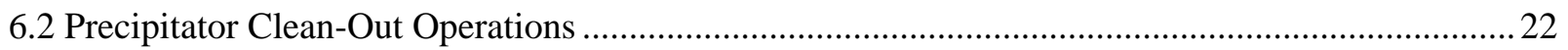

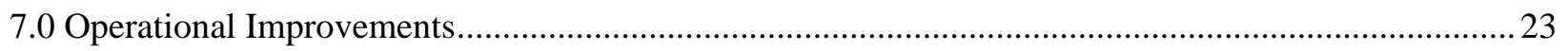

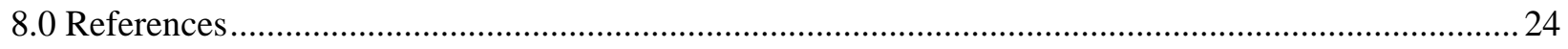

9.0 APPENDIX

9.1 Gas-Volume Collection Data from Process Flowsheet Tests.......................................................25 


\section{LIST OF TABLES}

Table 3-1. Experimental Solutions for Oxalic Acid Titration................................................................... 3

Table 3-2. Experimental Solutions for Process Flowsheet Testing .........................................................5

Table 3-3. Experimental Solutions for Precipitator Clean-Out Testing ................................................... 7

Table 4-1. Times (M:SS) of Solution Color Observations for $1.0 \mathrm{M} \mathrm{HNO}_{3}$ Test.....................................8

Table 4-2. Solution Analyses for Oxalate Titration Experiments …....................................................... 9

Table 4-3. Process Behavior Based on Solution Analyses ..................................................................... 10

Table 4-4. Solution Concentrations for Process Flowsheet Tests.......................................................... 11

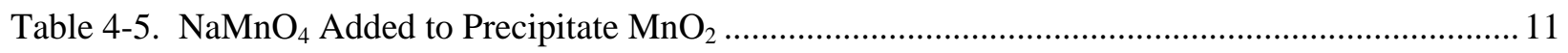

Table 4-6. Total Gas Volumes from Process Flowsheet Testing............................................................ 14

Table 4-7. Gas Analyses from Process Flowsheet Testing ................................................................... 15

Table 4-8. Initial and Maximum Temperatures during Process Flowsheet Testing ................................. 15

Table 4-9. Sodium Nitrite Addition Data and Calculations for Process Flowsheet Tests .........................16

Table 4-10. Solution Data during Sodium Nitrite Addition................................................................... 16

Table 4-11. Sodium Nitrite Addition Data and Calculations for Precipitator Clean-Out Tests................. 19

\section{LIST OF FIGURES}

Figure 3-1. Process Flowsheet Test Equipment....................................................................................... 4

Figure 3-2. Solutions after $\mathrm{MnO}_{2}$ Precipitation and Settling ............................................................. 6

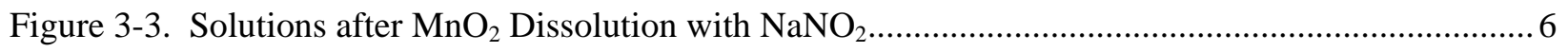

Figure 4-1. Gas Generation Data for Process Flowsheet Tests............................................................. 13

Figure 4-2. Gas Generation Rates for Process Flowsheet Tests .......................................................... 14

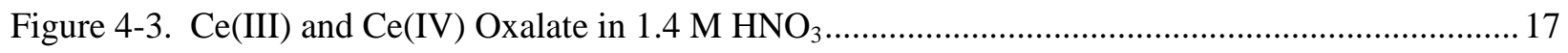

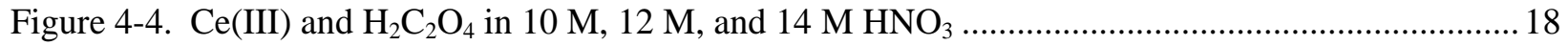

Figure 4-5. $\mathrm{Ce}(\mathrm{III})$ and $\mathrm{H}_{2} \mathrm{C}_{2} \mathrm{O}_{4}$ in $10 \mathrm{M}, 12 \mathrm{M}$, and $14 \mathrm{M} \mathrm{HNO}_{3}$ after First $\mathrm{NaMnO}_{4}$ Aliquot ............... 18

Figure 4-6. $\mathrm{Ce}(\mathrm{III})$ and $\mathrm{H}_{2} \mathrm{C}_{2} \mathrm{O}_{4}$ in $10 \mathrm{M}, 12 \mathrm{M}$, and $14 \mathrm{M} \mathrm{HNO}_{3}$ after $21 \mathrm{NaMnO}_{4}$ Aliquots ................. 19

Figure 6-1. Comparison of $\mathrm{MnO}_{2}$ Solids (left) and $\mathrm{Pu}(\mathrm{IV})$ Oxalate Solids (right) ................................. 23 


\section{LIST OF ABBREVIATIONS}

$\begin{array}{ll}\text { DI } & \text { deionized } \\ \text { GC } & \text { gas chromatography } \\ \text { ICPES } & \text { inductively coupled plasma emission spectroscopy } \\ \text { IC } & \text { ion chromatography } \\ \text { rpm } & \text { revolutions per minute } \\ \text { SRNL } & \text { Savannah River National Laboratory }\end{array}$




\subsection{Overview}

During HB-Line $\mathrm{Pu}-239$ operations, plutonium $(\mathrm{Pu})$ is precipitated as plutonium(IV) oxalate $\left[\mathrm{Pu}\left(\mathrm{C}_{2} \mathrm{O}_{4}\right)_{2}\right]$ using oxalic acid $\left(\mathrm{H}_{2} \mathrm{C}_{2} \mathrm{O}_{4}\right)$. An excess amount of $\mathrm{H}_{2} \mathrm{C}_{2} \mathrm{O}_{4}$ is used. Following the removal of precipitate by filtration, the filtrate is discharged to $\mathrm{H}$-Canyon. The receipt tank for the filtrate in H-Canyon is not geometrically favorable. With $\mathrm{H}_{2} \mathrm{C}_{2} \mathrm{O}_{4}$ present, the potential exists for the precipitation of $\mathrm{Pu}\left(\mathrm{C}_{2} \mathrm{O}_{4}\right)_{2}$ in the $\mathrm{H}$-Canyon receipt tank; this presents a criticality-control concern. One mitigating strategy entails oxidizing the excess $\mathrm{H}_{2} \mathrm{C}_{2} \mathrm{O}_{4}$ with sodium permanganate $\left(\mathrm{NaMnO}_{4}\right)$ in HB-Line. A second reaction employed in the flowsheet is the reaction of sodium nitrite $\left(\mathrm{NaNO}_{2}\right)$ with excess $\mathrm{NaMnO}_{4}$ to eliminate the presence of manganese dioxide $\left(\mathrm{MnO}_{2}\right)$ solids which form as a result of excess $\mathrm{NaMnO}_{4}$ addition.

A previous HB-Line flowsheet for $\mathrm{Pu}-239$ operations incorporated an $\mathrm{H}_{2} \mathrm{C}_{2} \mathrm{O}_{4}$ destruction step using permanganate. $^{[1]}$ However, the reference flowsheet accounted for the presence of hydrazine and ascorbic acid in solution with the excess $\mathrm{H}_{2} \mathrm{C}_{2} \mathrm{O}_{4}$. The current HB-Line flowsheet omits hydrazine and ascorbic acid, and precipitates plutonium as $\mathrm{Pu}(\mathrm{IV})$ oxalate instead of $\mathrm{Pu}(\mathrm{III}) .{ }^{[2]}$ It is expected that the flowsheet volumes and addition rates for $\mathrm{NaMnO}_{4}$ can be adjusted to yield a more efficient process and result in waste minimization.

HB-Line Engineering requested the Savannah River National Laboratory (SRNL) to investigate the applicability of the previous oxalate destruction chemistry to the current flowsheet. ${ }^{[3]}$ The SRNL investigation should verify both the quantities and addition rates of $\mathrm{NaMnO}_{4}$ and $\mathrm{NaNO}_{2}$ required to completely react excess oxalic acid and $\mathrm{MnO}_{2}$ solids without over-pressurization of the reaction vessel.

\subsection{Quality Assurance}

The task technical approach and quality assurance requirements are described in a Task Technical and Quality Assurance Plan. ${ }^{[4]}$ Requirements for performing reviews of technical reports and the extent of review are established in manual E7, 2.60. SRNL documents the extent and type of review using the SRNL Technical Report Design Checklist contained in WSRC-IM-2002-00011, Rev. 2.

\subsection{Background}

The $\mathrm{H}_{2} \mathrm{C}_{2} \mathrm{O}_{4}$ destruction reaction depends upon the reaction of permanganate ion $\left[\mathrm{MnO}_{4}^{-}\right]$with $\mathrm{H}_{2} \mathrm{C}_{2} \mathrm{O}_{4}$. Previous studies at SRNL observed the oxidation of $\mathrm{H}_{2} \mathrm{C}_{2} \mathrm{O}_{4}$ in a solution that also included the presence of hydrazine and ascorbic acid. ${ }^{[5][6]}$ The specific reaction of permanganate with $\mathrm{H}_{2} \mathrm{C}_{2} \mathrm{O}_{4}$ was obscured by reactions of permanganate with the other components, particularly the ascorbic acid. The work by Gray ${ }^{[6]}$ became the basis for the HB-Line $\mathrm{Pu}-239$ processing flowsheets. ${ }^{[1][2]}$

In this study, two types of experiments were performed to evaluate the flowsheet - titrations and process flowsheet tests. Titrations involve the careful addition of one compound to another where the end point of the reaction is depicted by a physical change, such as color or the appearance of a precipitate. Process flowsheet tests approximated the process conditions and flow rates of the HB-Line process as a means of validating the flowsheet. Ten titrations and nine process flowsheet tests were completed.

\subsection{Chemistry}

According to the literature, the oxidation of $\mathrm{H}_{2} \mathrm{C}_{2} \mathrm{O}_{4}$ by permanganate $\left[\mathrm{MnO}_{4}{ }^{-}\right.$or $\left.\mathrm{Mn}(\mathrm{VII})\right]$ involves three concurrent chemical reactions. ${ }^{[7]}$ The first reaction is the reaction of $\mathrm{Mn}$ (VII) directly with $\mathrm{H}_{2} \mathrm{C}_{2} \mathrm{O}_{4}$ to form the manganese (II) ion, carbon dioxide $\left(\mathrm{CO}_{2}\right)$, and water $\left(\mathrm{H}_{2} \mathrm{O}\right)$. This first reaction is slow. Although Mn ions will take a different form in $\mathrm{HNO}_{3}$, the first reaction has been written according to the conventions of the literature article as Reaction $1 .{ }^{[7]}$

$$
2 \mathrm{Mn}(\mathrm{OH})_{7}+5 \mathrm{H}_{2} \mathrm{C}_{2} \mathrm{O}_{4} \rightarrow 2 \mathrm{Mn}(\mathrm{OH})_{2}+10 \mathrm{CO}_{2}+10 \mathrm{H}_{2} \mathrm{O}
$$


The second reaction requires the presence of the $\mathrm{Mn}(\mathrm{II})$ ion [written as the $\mathrm{Mn}(\mathrm{OH})_{2}$ species]. It involves the reaction of $\mathrm{Mn}(\mathrm{VII})$ with $\mathrm{Mn}(\mathrm{II})$ to yield manganese dioxide [shown as the $\mathrm{Mn}(\mathrm{OH})_{4}$ species in the literature article for Reaction 2]. Reaction 2 is a very fast reaction. ${ }^{[7]}$

$$
3 \mathrm{Mn}(\mathrm{OH})_{2}+2 \mathrm{Mn}(\mathrm{OH})_{7} \rightarrow 5 \mathrm{Mn}(\mathrm{OH})_{4}
$$

The third reaction is the oxidation of oxalic acid by $\mathrm{MnO}_{2}$ [Mn(IV)]. The reaction, shown as Reaction 3, is also a fast reaction, but not as fast as Reaction $2 .{ }^{[7]}$

$$
\mathrm{Mn}(\mathrm{OH})_{4}+\mathrm{H}_{2} \mathrm{C}_{2} \mathrm{O}_{4} \rightarrow \mathrm{Mn}(\mathrm{OH})_{2}+2 \mathrm{CO}_{2}+2 \mathrm{H}_{2} \mathrm{O}
$$

The combination of Reactions 2 and 3 yields Reaction 1; however, Reactions 2 and 3 occur at a much faster rate than Reaction 1. The net effect of the three reactions is that there is an observed incubation period at the outset of the process chemistry while Reaction 1 occurs and provides a source of Mn(II) for Reactions 2 and 3. It has been observed that the overall reaction rate increases as $\mathrm{H}_{2} \mathrm{C}_{2} \mathrm{O}_{4}$ is oxidized due to the increasing $\mathrm{Mn}$ (II) concentration for Reaction 2. Last, Reaction 2 depicts that at the conclusion of the reaction, when all $\mathrm{H}_{2} \mathrm{C}_{2} \mathrm{O}_{4}$ has been consumed, excess $\mathrm{Mn}$ (VII) will react rapidly with $\mathrm{Mn}$ (II) to form $\mathrm{MnO}_{2}$ solids, which are brown. There will be no measurable excess Mn(VII) until all of the Mn(II) has been converted to $\mathrm{MnO}_{2}$ via Reaction 2. Therefore, driving the reaction to a condition of measureable excess $\mathrm{Mn}(\mathrm{VII})$ is not necessary.

The reaction for dissolving $\mathrm{MnO}_{2}$ with $\mathrm{NaNO}_{2}$ is as follows. ${ }^{[5]}$

$$
\mathrm{MnO}_{2}+\mathrm{NaNO}_{2}+2 \mathrm{H}^{+} \rightarrow \mathrm{Mn}^{2+}+\mathrm{NaNO}_{3}+\mathrm{H}_{2} \mathrm{O}
$$

A competing reaction for $\mathrm{NaNO}_{2}$, particularly in high-acid conditions, decomposes $\mathrm{NaNO}_{2}$ and is accompanied by the release of brown nitrogen dioxide $\left(\mathrm{NO}_{2}\right)$ gas. The NO gas generated by the reaction is converted to $\mathrm{NO}_{2}$ by reaction with oxygen gas in the air.

$$
2 \mathrm{NaNO}_{2}+2 \mathrm{HNO}_{3} \rightarrow 2 \mathrm{NaNO}_{3}+\mathrm{H}_{2} \mathrm{O}+\mathrm{NO}_{2}+\mathrm{NO}
$$

\subsection{Process Flowsheet}

The proposed flowsheet for Pu recovery operations will yield a filtrate solution of 58.8 liters with $1.4 \mathrm{M}$ nitric acid $\left(\mathrm{HNO}_{3}\right)$ and $0.1 \mathrm{M} \mathrm{H}_{2} \mathrm{C}_{2} \mathrm{O}_{4}$. Based on the results from Gray ${ }^{[6]}$, the proposed flowsheet assumed that three moles of $\mathrm{H}_{2} \mathrm{C}_{2} \mathrm{O}_{4}$ react with two moles of $\mathrm{NaMnO}_{4}$ to yield two moles of $\mathrm{MnO}_{2}$ plus $\mathrm{CO}_{2}$ and water $\left(\mathrm{H}_{2} \mathrm{O}\right)$; excess $\mathrm{NaMnO}_{4}(10 \%)$ would also be added. Excess $\mathrm{NaMnO}_{4}$ and $\mathrm{MnO}_{2}$ are then reacted with $\mathrm{NaNO}_{2}$ to produce the $\mathrm{Mn}(\mathrm{II})$ ion. The amount of $\mathrm{NaNO}_{2}$ added is based on adding one mole of $\mathrm{NaNO}_{2}$ per mole of $\mathrm{MnO}_{2}$ and 2.5 moles of $\mathrm{NaNO}_{2}$ per mole of unreacted $\mathrm{NaMnO}_{4}$ plus $25 \%$ excess.

Based on these flowsheet assumptions, there will be 5.88 moles of $\mathrm{H}_{2} \mathrm{C}_{2} \mathrm{O}_{4}$ in the filtrate solution. Based on previous assumptions, ${ }^{[6]}$ to that would be added 3.92 moles of $\mathrm{NaMnO}_{4}$ to react the $\mathrm{H}_{2} \mathrm{C}_{2} \mathrm{O}_{4}$ and $10 \%$ excess, or 0.39 moles of $\mathrm{NaMnO}_{4}$ (total of 4.31 moles $\mathrm{NaMnO}_{4}$ ). The reaction would yield 3.92 moles of $\mathrm{MnO}_{2}$ and 0.39 moles of unreacted $\mathrm{NaMnO}_{4}$. The $\mathrm{MnO}_{2}$ would be reacted with 3.92 moles of $\mathrm{NaNO}_{2}$ and the excess $\mathrm{NaMnO}_{4}$ would be reacted with 0.98 moles of $\mathrm{NaNO}_{2}$, or 4.90 moles of $\mathrm{NaNO}_{2}$. Allowing for $25 \%$ excess (1.22 moles), the total $\mathrm{NaNO}_{2}$ added would be 6.12 moles.

However, based on Reactions 1-3, ${ }^{[7]}$ the decomposition of 5.88 moles of $\mathrm{H}_{2} \mathrm{C}_{2} \mathrm{O}_{4}$ requires 2.35 moles of $\mathrm{NaMnO}_{4}$ plus 0.24 moles excess, or 2.59 moles total $\mathrm{NaMnO}_{4}$ (compared to 4.31 moles above). The reaction of $\mathrm{MnO}_{2}$ and $\mathrm{NaMnO}_{4}$ to $\mathrm{Mn}$ (II) requires 2.59 moles of $\mathrm{NaNO}_{2}$ plus 0.74 moles excess, or 3.33 moles total $\mathrm{NaNO}_{2}$ (compared to 6.12 moles above). 


\subsection{Precipitator Tank Clean Out}

Periodically, the precipitator tanks will have to be cleaned of residual $\mathrm{Pu}\left(\mathrm{C}_{2} \mathrm{O}_{4}\right)_{2}$. The proposed solution for clean out is $14 \mathrm{M} \mathrm{HNO}_{3}$. Clean out of the precipitator will occur when the accountability system calculates the presence of $360 \mathrm{~g}$ of Pu in the precipitator tank, or sooner as needed. To protect against a maximum Pu concentration of $60 \mathrm{~g} / \mathrm{L}$, the volume of solution used for the precipitator tank clean out will be 12 liters, resulting in an expected Pu concentration of less than $30 \mathrm{~g} / \mathrm{L}$. The oxalate associated with these $\mathrm{Pu}\left(\mathrm{C}_{2} \mathrm{O}_{4}\right)_{2}$ solids must be oxidized in a manner similar to what was described in Section 2.2. It is not known if Reactions 1-3 will apply to the oxidation of $\mathrm{Pu}\left(\mathrm{C}_{2} \mathrm{O}_{4}\right)_{2}$ in $14 \mathrm{M} \mathrm{HNO}_{3}$. The precipitator tank clean out steps will be repeated until the tank has been adequately cleared of residual Pu precipitate.

\subsection{Experimental Procedure}

\subsection{Stock Solution Preparation}

Two stock solutions were prepared for the majority of the experiments. The first solution was 40 wt \% $\mathrm{NaMnO}_{4}-\mathrm{H}_{2} \mathrm{O}$ in deionized (DI) water $\left(\mathrm{H}_{2} \mathrm{O}\right)$. I weighed $27.1823 \mathrm{~g}$ of $\mathrm{NaMnO}_{4}-\mathrm{H}_{2} \mathrm{O}$ (Strem Chemicals, $98 \%$ min. purity) into a glass jar. To the jar was added 40.8020 g of $\mathrm{DI}_{2} \mathrm{O}$ and a Teflon ${ }^{\mathrm{TM}}$-coated stir bar. The jar was covered and the contents stirred for more than $24 \mathrm{~h}$. Five individual 5.00 -mL aliquots of the jar were withdrawn and weighed. The average weight of the five samples was $6.6194 \mathrm{~g}$ (density of $1.324 \mathrm{~g} / \mathrm{mL}$ ). Based on the density, the calculated concentration of the $\mathrm{NaMnO}_{4}$ solution was $3.31 \mathrm{M}$. The glass jar was stored in a stainless steel beaker to limit light into the glass jar.

The second stock solution was $5.65 \mathrm{M} \mathrm{NaNO}_{2}$. I added $19.4920 \mathrm{~g}$ of $\mathrm{NaNO}_{2}$ (Fisher Scientific, 99.6\% purity) to a 50-mL volumetric flask and filled the flask with $\mathrm{DI} \mathrm{H}_{2} \mathrm{O}$ to the line. A micro stir bar was added to the flask and the flask stirred until the contents dissolved. The stir bar was removed and the volume in the flask brought up to the $50-\mathrm{mL}$ line using DI $\mathrm{H}_{2} \mathrm{O}$. The flask was capped and shaken to yield a uniform mixture.

\subsection{Oxalate Titration}

In the first phase of testing, four solutions of $0.15 \mathrm{M} \mathrm{H}_{2} \mathrm{C}_{2} \mathrm{O}_{4}-2 \mathrm{H}_{2} \mathrm{O}$ in $\mathrm{HNO}_{3}$ were titrated with $\mathrm{NaMnO}_{4}$ to compare behavior with that reported in the literature. ${ }^{[7]}$ Three $\mathrm{HNO}_{3}$ concentrations were tested in parallel - 1.5 M, 4.0 M, and 6.0 M. Three experimental solutions were prepared in 100-mL volumetric flasks by combining the contents listed in Table 3-1. A fourth experiment was performed afterwards at $1.0 \mathrm{M} \mathrm{HNO}_{3}$. All solids were completely dissolved prior to titration.

Table 3-1. Experimental Solutions for Oxalic Acid Titration

\begin{tabular}{||c|c|c|c||}
\hline $\begin{array}{c}\mathbf{H N O}_{3} \\
(\mathbf{M})\end{array}$ & $\begin{array}{c}\mathbf{H}_{2} \mathbf{C}_{2} \mathbf{O}_{\mathbf{4}}-\mathbf{2 H}_{\mathbf{2}} \mathbf{O} \\
\mathbf{( g )}\end{array}$ & $\begin{array}{c}\mathbf{1 5 . 7} \mathbf{\mathbf { M ~ H N O }} \\
\mathbf{( \mathbf { m L } )}\end{array}$ & DI $\mathbf{H}_{\mathbf{2}} \mathbf{O}(\mathbf{m L})$ \\
\hline 1.5 & 1.8928 & 9.6 & To $100 \mathrm{~mL}$ \\
\hline 4.0 & 1.8923 & 25.5 & To $100 \mathrm{~mL}$ \\
\hline 6.0 & 1.8920 & 38.2 & To $100 \mathrm{~mL}$ \\
\hline 1.0 & 3.7856 & 12.7 & To $200 \mathrm{~mL}$ \\
\hline
\end{tabular}

The three solutions were placed into individual 250-mL Erlenmeyer flasks along with a Teflon ${ }^{\mathrm{TM}}$-coated stir bar. The $1.0 \mathrm{M}$ solution was placed into a $1000-\mathrm{mL}$ beaker. Each container was placed on a hot plate-stirrer and the stirrer speed set to $300 \mathrm{rpm}$ (revolutions per minute). No heating was applied to the solution. Calculations determined that $1810 \mu \mathrm{L}$ of $3.31 \mathrm{M} \mathrm{NaMnO}_{4}$ stock solution would be required to completely convert the $\mathrm{H}_{2} \mathrm{C}_{2} \mathrm{O}_{4}$ to $\mathrm{CO}_{2}$ and $\mathrm{H}_{2} \mathrm{O}$ according to Reactions 1-3 (3620 $\mu \mathrm{L}$ for $1.0 \mathrm{M}$ test). Therefore, $\mathrm{NaMnO}_{4}$ solution was added to each flask in $90.5 \mu \mathrm{L}$ aliquots (181.0 $\mu \mathrm{L}$ for the $1.0 \mathrm{M}$ test) 
using a Rainin $1000 \mu \mathrm{L}$ adjustable pipette. The setting of the pipette was verified every 15-20 aliquots by pipetting DI $\mathrm{H}_{2} \mathrm{O}$ from a beaker on a balance and weighing the mass of water removed by the pipette. The pipette setting was stable throughout the experiments.

For each aliquot added, when the $\mathrm{NaMnO}_{4}$ enters the solution, the solution turns either dark purple or dark brown. Typically, within three minutes of introducing an aliquot, the solution clears. When the solution clears, another aliquot of $\mathrm{NaMnO}_{4}$ is added to the flask. After 10 aliquots, a sample was collected from each flask for analysis by ion chromatography (IC) for anions and inductively coupled plasma emission spectroscopy (ICPES) for cations. When the dark brown color persisted past three minutes, the end point of the reaction was reached, and a sample collected. An additional $10 \%$ excess $\mathrm{NaMnO}_{4}$ was then added, the solution stirred for more than three minutes, and the solution sampled.

\subsection{Process Flowsheet Testing}

Process flowsheet testing entailed repeating the general approach discussed in Section 3.2. Differences included 1) the $\mathrm{NaMnO}_{4}$ was metered in using a syringe pump, 2) the solution temperature was monitored, 3) the gas generation volume was measured, and 4) cerium (Ce) was used as a surrogate for Pu. The apparatus is shown in Figure 3-1.

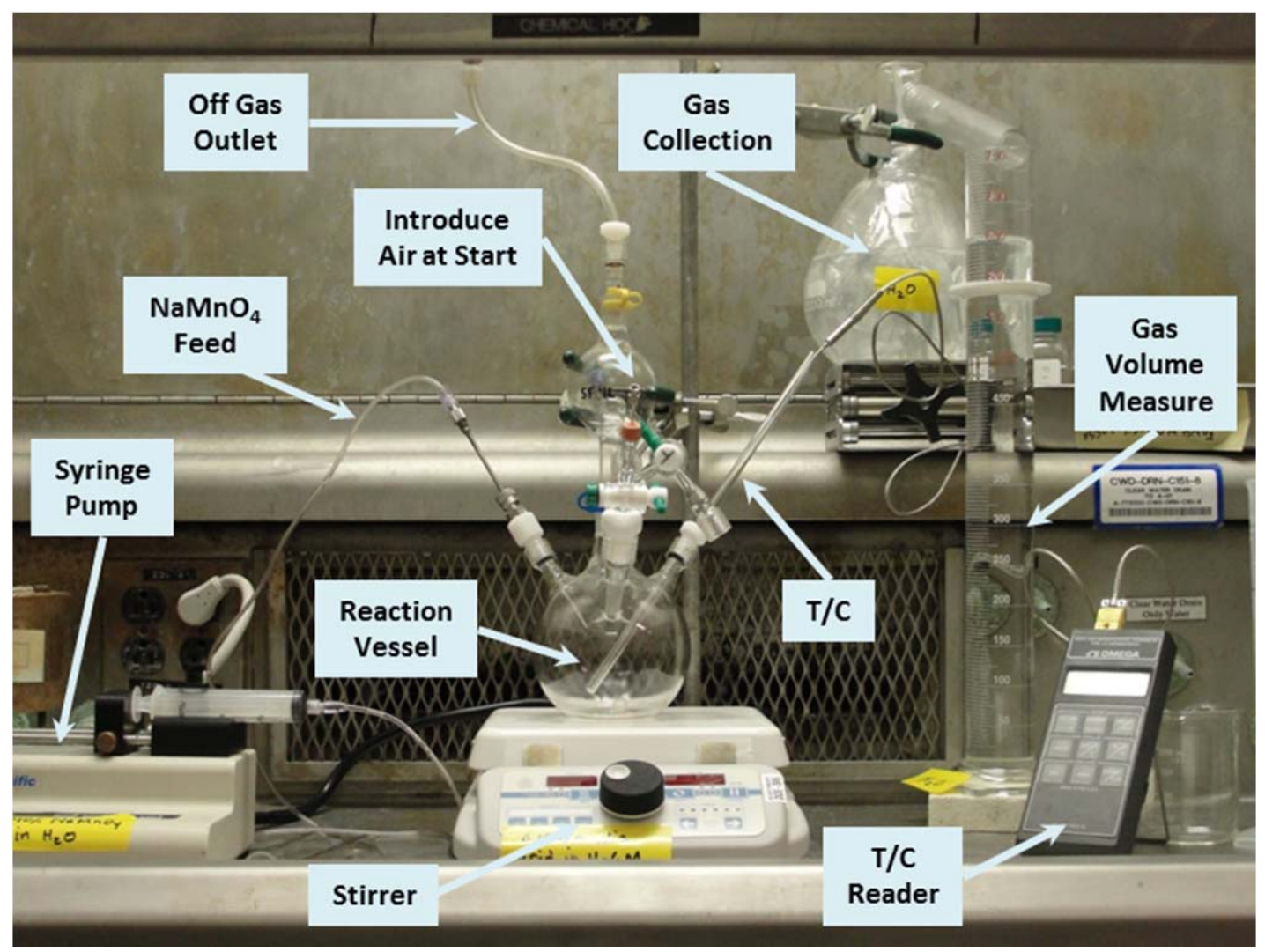

Figure 3-1. Process Flowsheet Test Equipment

Temperature was measured using a Type $\mathrm{K}$ thermocouple connected to an Omega Engineering Model HH22 thermocouple reader. Sodium permanganate solution was fed to the reaction vessel using a KD Scientific Model 780100 syringe pump. The syringe was fabricated from high density polyethylene. The $\mathrm{NaMnO}_{4}$ feed line into the reaction vessel was $304 \mathrm{~L}$ stainless steel. The tubing between the syringe and 
stainless steel feed line was made of clear Tygon ${ }^{\mathrm{TM}}$. Gas was collected in a Tedlar ${ }^{\mathrm{TM}}$ bag, and the gas volume was measured using water displacement to a graduated cylinder.

Eight experiments were conducted in the following manner. Each test solution was prepared separately by combining $\mathrm{H}_{2} \mathrm{C}_{2} \mathrm{O}_{4}-2 \mathrm{H}_{2} \mathrm{O}(0.15 \mathrm{M})$, cerous nitrate [Ce( $\left(\mathrm{NO}_{3}\right)_{3}-6 \mathrm{H}_{2} \mathrm{O}$ ], $15.7 \mathrm{M} \mathrm{HNO}_{3}$, and DI water to the 100-mL mark in a 100-mL volumetric flask according to the amounts listed in Table 3-2. Test P7 simulates process operations in which a tank heel from the previous oxalate-kill operation is mixed with the incoming filtrate solution. Similarly, Test P8 simulates process operations in which a tank heel from a previous precipitator clean-out operation is mixed with the incoming filtrate solution.

When all solids were dissolved, the contents of the flask were added to the reaction vessel (Figure 3-1). The stirrer speed was set to $300 \mathrm{rpm}$. Stock $\mathrm{NaMnO}_{4}$ solution was drawn into the syringe through the entire feed line and the $\mathrm{NaMnO}_{4}$ feed assembly was attached to the apparatus. For Test $\mathrm{P} 5$, the $\mathrm{NaMnO}_{4}$ feed was prepared by dissolving $2.6380 \mathrm{~g}$ of $\mathrm{NaMnO}_{4}-\mathrm{H}_{2} \mathrm{O}$ in water to a final volume of $10 \mathrm{~mL}$. The system was sealed. Using a sealed gas syringe attached to a side port, air was introduced into the system until water overflowed from the gas collection flask into the gas volume measurement flask. The system was then sealed again.

Table 3-2. Experimental Solutions for Process Flowsheet Testing

\begin{tabular}{|c|c|c|c|c|c|c|c|}
\hline $\begin{array}{c}\text { Test } \\
\#\end{array}$ & $\begin{array}{l}\text { Test } \\
\text { Order }\end{array}$ & $\begin{array}{l}\mathrm{H}_{2} \mathrm{C}_{2} \mathrm{O}_{4^{-}} \\
2 \mathrm{H}_{2} \mathrm{O}(\mathrm{g})\end{array}$ & $\begin{array}{l}\mathrm{Ce}\left(\mathrm{NO}_{3}\right)_{3^{-}} \\
6 \mathrm{H}_{2} \mathrm{O}(\mathrm{g})\end{array}$ & $\begin{array}{c}15.7 \mathrm{M} \\
\mathrm{HNO}_{3}(\mathrm{~mL})\end{array}$ & $\begin{array}{c}\text { Extra } \\
\text { Solution }\end{array}$ & $\begin{array}{c}\mathrm{NaMnO}_{4} \\
(\mathrm{M})\end{array}$ & $\begin{array}{c}\mathrm{NaMnO}_{4} \\
\text { Rate }(\mathrm{mL} / \mathrm{h})\end{array}$ \\
\hline $\mathrm{P} 1$ & 1 & 1.8938 & --- & 25.5 & --- & 3.31 & 11.8 \\
\hline $\mathrm{P} 2$ & 2 & 1.8918 & --- & 9.6 & --- & 3.31 & 11.8 \\
\hline P3 & 3 & 1.8936 & $-\overline{--}$ & 38.2 & $\begin{array}{l}-- \\
--\end{array}$ & 3.31 & 11.8 \\
\hline $\mathrm{P} 4$ & 4 & 1.8918 & --- & 8.9 & --- & 3.31 & 3.9 \\
\hline $\mathrm{P} 5$ & 8 & 1.8917 & --- & 8.9 & --- & 1.65 & 11.8 \\
\hline P6 & 5 & 1.9010 & 0.0174 & 8.9 & --- & 3.31 & 11.8 \\
\hline P7 & 7 & 1.8923 & --- & 8.9 & $\begin{array}{c}9.1 \mathrm{~mL} \text { from } \\
\text { Test P4 }\end{array}$ & 3.31 & 11.8 \\
\hline P8 & 6 & 1.8927 & --- & 8.9 & $\begin{array}{c}9.1 \mathrm{~mL} \text { of } \\
14 \mathrm{M} \mathrm{HNO}_{3}\end{array}$ & 3.31 & 11.8 \\
\hline P9* & 9 & 1.9990 & 4.1809 & 35.8 & --- & 3.31 & 11.8 \\
\hline
\end{tabular}

Flow of $\mathrm{NaMnO}_{4}$ solution was initiated by starting the syringe pump. When the first drop of $\mathrm{NaMnO}_{4}$ was noted in the reaction vessel, the experiment timer was started and the total volume of feed noted on the pump display was recorded. Temperature and gas volume data were collected frequently (typically every 15 seconds). When the solution in the reaction vessel ceased reacting with the $\mathrm{NaMnO}_{4}$ feed, the total feed on the pump display was recorded. Ten percent excess $\mathrm{NaMnO}_{4}$ was added to the reaction vessel before $\mathrm{NaMnO}_{4}$ feed was discontinued and the total volume of feed on the pump display recorded.

The syringe was emptied of $\mathrm{NaMnO}_{4}$ stock solution into the original storage bottle, and the feed line was cleaned with DI $\mathrm{H}_{2} \mathrm{O}$ and air until the line was clear. For Tests P1, P2, P3, P6, P7, and P8, end solution samples were collected for IC anion and ICPES. For Tests P1, P2, and P3, gas samples were collected for analysis by gas chromatography (GC). The remaining test solution for each experiment was stored in a separate glass jar. At this stage of testing, each test solution contained $\mathrm{MnO}_{2}$ solids which, if agitated, made the solution dark brown. Figure 3-2 shows the solutions from Tests P1 (4.0 M HNO $)$, P2 (1.5 M $\left.\mathrm{HNO}_{3}\right)$, and $\mathrm{P} 3\left(6.0 \mathrm{M} \mathrm{HNO}_{3}\right)$ after $\mathrm{MnO}_{2}$ precipitated and settled. 


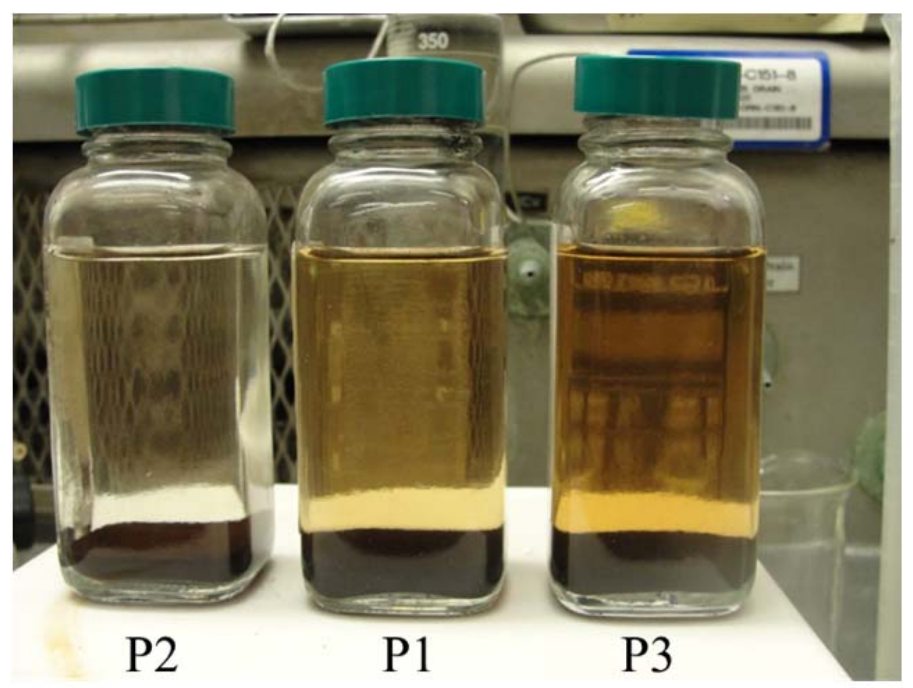

Figure 3-2. Solutions after $\mathrm{MnO}_{2}$ Precipitation and Settling

The resulting test solutions were subsequently reacted with the $5.65 \mathrm{M} \mathrm{NaNO}_{2}$ stock solution until the $\mathrm{MnO}_{2}$ solids dissolved. For Tests P1, P2, and P3, the $\mathrm{NaNO}_{2}$ solution was added using a pipette with intermittent sampling for IC anions and ICPES. With Test P1, $197.5 \mu \mathrm{L}$ of $\mathrm{NaNO}_{2}$ was added, a sample collected, two 197.5- $\mu \mathrm{L}$ aliquots of $\mathrm{NaNO}_{2}$ were added, a sample collected, and $100 \mu \mathrm{L}$ of $\mathrm{NaNO}_{2}$ added followed by sampling. For Test P2, two 80.5- $\mu \mathrm{L}$ aliquots of $\mathrm{NaNO}_{2}$ were added, a sample collected, four 80.5- $\mu \mathrm{L}$ aliquots of $\mathrm{NaNO}_{2}$ were added, a sample collected, and $100 \mu \mathrm{L}$ of $\mathrm{NaNO}_{2}$ added followed by sampling. In Test $\mathrm{P} 3$, three $78.0-\mu \mathrm{L}$ aliquots of $\mathrm{NaNO}_{2}$ were added, a sample collected, four 78.0- $\mu \mathrm{L}$ aliquots of $\mathrm{NaNO}_{2}$ were added, a sample collected, and $100 \mu \mathrm{L}$ of $\mathrm{NaNO}_{2}$ added followed by sampling. In each of the above tests, the second sample corresponded to the complete dissolution of the $\mathrm{MnO}_{2}$ solids. The test solutions following $\mathrm{MnO}_{2}$ dissolution are depicted in Figure 3-3.

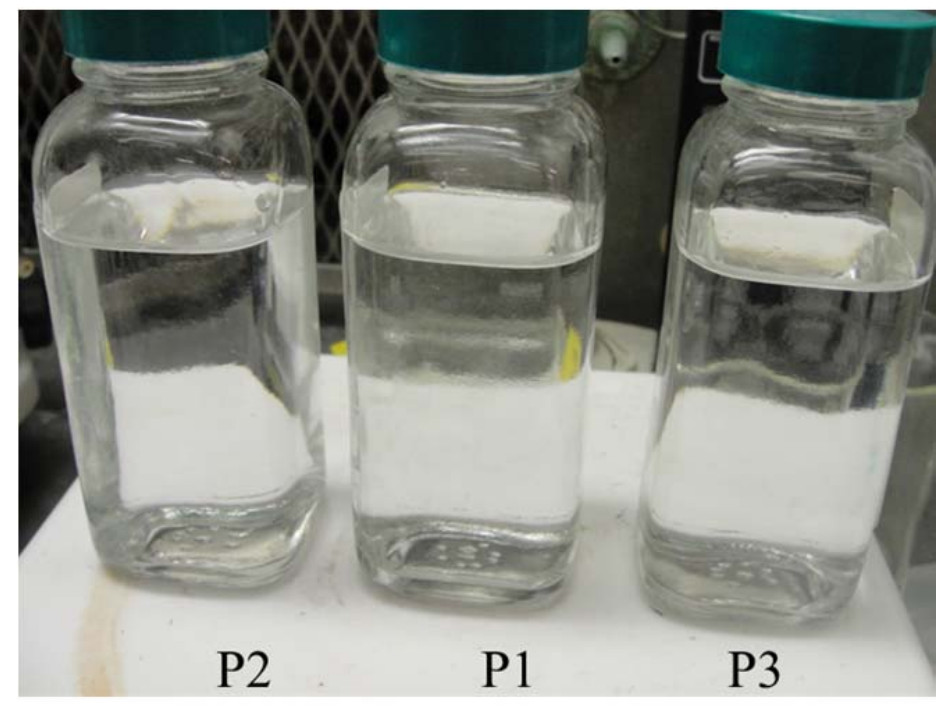

Figure 3-3. Solutions after $\mathrm{MnO}_{2}$ Dissolution with $\mathrm{NaNO}_{2}$ 
For Tests P4-P8, $\mathrm{NaNO}_{2}$ solution was added using a burette. Sodium nitrite solution was added until the $\mathrm{MnO}_{2}$ solids disappeared, a sample was collected for IC and ICPES, 25\% excess $\mathrm{NaNO}_{2}$ was added, and a final sample collected. For Test P8, only an end sample was collected. For Test P5, no samples were obtained during $\mathrm{NaNO}_{2}$ addition.

\subsection{Precipitator Tank Clean-Out Solution}

Experiments evaluating the behavior of the precipitator clean-out solution are variations of the titration tests described in Section 3.2 and the process flowsheet tests described in Section 3.3. The principle variation for precipitator clean-out tests is the presence of significant quantities of $\mathrm{Ce}$, a surrogate for $\mathrm{Pu}$, in the $\mathrm{HNO}_{3}-\mathrm{H}_{2} \mathrm{C}_{2} \mathrm{O}_{4}$ solution. Quantities of Ce simulate the molar equivalent of $57.1 \mathrm{~g} / \mathrm{L}$ Pu for tests with $\mathrm{Ce}(\mathrm{III})$ and $42.8 \mathrm{~g} / \mathrm{L} \mathrm{Pu}$ for the test with $\mathrm{Ce}(\mathrm{IV})$. Cerium (III) was added as $\mathrm{Ce}\left(\mathrm{NO}_{3}\right)_{3}-6 \mathrm{H}_{2} \mathrm{O}$ (AlfaAesar, 99.5\% purity); the source for Ce(IV) was ceric ammonium nitrate $\left[\left(\mathrm{NH}_{4}\right)_{2} \mathrm{Ce}\left(\mathrm{NO}_{3}\right)_{6}\right]$ (J. T. Baker, 99.8\% purity). Quantities of $\mathrm{H}_{2} \mathrm{C}_{2} \mathrm{O}_{4}$ were based on the precipitating oxalate species plus $10 \%$ molar excess; the $\mathrm{H}_{2} \mathrm{C}_{2} \mathrm{O}_{4}$ concentration was maintained for each test.

Six titration tests and one process flowsheet test were completed. The chemical make-up of each titration test, prepared, is shown in Table 3-3. In each test, a portion of the acid was used to dissolve the $\mathrm{H}_{2} \mathrm{C}_{2} \mathrm{O}_{4}$ $2 \mathrm{H}_{2} \mathrm{O}$ and the remainder of the acid was used to dissolve the Ce salt. Once both components dissolved completely, the two acid solutions were combined. The volume was adjusted to $50 \mathrm{~mL}$, and the solution stirred for 15-30 min to allow precipitation to occur. The $\mathrm{H}_{2} \mathrm{C}_{2} \mathrm{O}_{4}$ was then reacted with $3.31 \mathrm{M} \mathrm{NaMnO}_{4}$, which was pipetted into the solution in $120 \mu \mathrm{L}$ aliquots. As described in Section 3.2, the end point was determined by the persistence of a brown $\mathrm{MnO}_{2}$ precipitate in the solution. When the end point was achieved, samples were obtained for analysis by IC anion and ICPES.

Table 3-3. Experimental Solutions for Precipitator Clean-Out Testing

\begin{tabular}{|c|c|c|c|c|}
\hline Test & $\begin{array}{c}\mathrm{H}_{2} \mathrm{C}_{2} \mathrm{O}_{4}-2 \mathrm{H}_{2} \mathrm{O} \\
(\mathrm{g})\end{array}$ & $\begin{array}{l}\mathrm{Ce}\left(\mathrm{NO}_{3}\right)_{3^{-}} \\
6 \mathrm{H}_{2} \mathrm{O} \text { (g) }\end{array}$ & $\begin{array}{l}\left(\mathrm{NH}_{4}\right)_{2} \mathrm{Ce}- \\
\left(\mathrm{NO}_{3}\right)_{6} \text { (g) }\end{array}$ & $\begin{array}{c}\mathrm{HNO}_{3} \\
(\mathrm{M})\end{array}$ \\
\hline A & 2.4844 & 5.1846 & -- & 1.4 \\
\hline $\mathrm{B}$ & 2.4837 & --- & 4.9065 & 1.4 \\
\hline $\mathrm{C}$ & 2.4868 & 5.1815 & --- & 10.0 \\
\hline $\mathrm{D}$ & 2.4870 & 5.1821 & --- & 12.0 \\
\hline $\mathrm{E}$ & 2.4860 & 5.1817 & --- & 14.0 \\
\hline $\mathrm{F}$ & 2.4874 & 5.1834 & --- & $14.0 \rightarrow 7.0^{*}$ \\
\hline
\end{tabular}

Tests C-F were subsequently reacted with $5.65 \mathrm{M} \mathrm{NaNO}_{2}$ in $25 \mu \mathrm{L}$ aliquots until the brown $\mathrm{MnO}_{2}$ solids dissolved. No samples were collected after addition of $\mathrm{NaNO}_{2}$.

Test P9 was a process flowsheet test run in a manner similar to that described in Section 3.3 using solution concentrations similar to Test $\mathrm{F}$. The test solution $(40 \mathrm{~mL})$ was prepared by combining $1.9990 \mathrm{~g}$ $\mathrm{H}_{2} \mathrm{C}_{2} \mathrm{O}_{4}-2 \mathrm{H}_{2} \mathrm{O}$, 4.1809 g Ce$\left(\mathrm{NO}_{3}\right)_{3}-6 \mathrm{H}_{2} \mathrm{O}, 35.8 \mathrm{~mL} 15.7 \mathrm{M} \mathrm{HNO}_{3}$ and $\mathrm{DI} \mathrm{H}_{2} \mathrm{O}$ to $40 \mathrm{~mL}$. The solution was mixed for $15 \mathrm{~min}$ at $300 \mathrm{rpm}$. To this solution was added $40 \mathrm{~mL}$ of DI $\mathrm{H}_{2} \mathrm{O}$ followed by an additional 30 min of stirring.

The oxalate in Test P9 was then reacted with $3.31 \mathrm{M} \mathrm{NaMnO}_{4}$ fed by the syringe pump at $11.8 \mathrm{~mL} / \mathrm{h}$. The gas from the reaction was collected. The temperature and gas release volume were recorded in 15-60 second intervals. After the end point was reached, $10 \%$ excess $\mathrm{NaMnO}_{4}$ was added. At this point of the 
test, the solution contained sufficient $\mathrm{MnO}_{2}$ solids to make the solution dark brown when agitated. The process solution with excess $\mathrm{NaMnO}_{4}$ was subsequently reacted with $5.65 \mathrm{M} \mathrm{NaNO}_{2}$ until the $\mathrm{MnO}_{2}$ solids dissolved completely. Since no samples were collected, no excess $\mathrm{NaNO}_{2}$ was added.

\subsection{Results and Discussion}

\subsection{Oxalate Titration}

Calculations based on Reactions 1-3 determined that $1810 \mu \mathrm{L}$ should be required to completely oxidize the $\mathrm{H}_{2} \mathrm{C}_{2} \mathrm{O}_{4}$ in solution. This quantity was arbitrarily divided by 20 to arrive at a targeted aliquot of 90.5 $\mu \mathrm{L}$ so that each aliquot could theoretically consume $5 \%$ of the $\mathrm{H}_{2} \mathrm{C}_{2} \mathrm{O}_{4}$. In all three experiments, brown $\mathrm{MnO}_{2}$ solids persisted in the solution (Figure 3-2) after addition of the $21^{\text {st }}$ aliquot, indicating the oxalate had been completely consumed. Two aliquots of excess were added (for a total of 23) after the end point was achieved.

Visual observations of the oxalate titration experiments indicate that the reactions discussed in Section 2.1 represent the system behavior. For all three tests $-1.5 \mathrm{M}, 4.0 \mathrm{M}$, and $6.0 \mathrm{M} \mathrm{HNO}_{3}$ - the initial system behavior is described by Reaction 1 . When the first aliquot of $\mathrm{NaMnO}_{4}$ was added to each solution, the solution remained dark purple for one to two minutes before changing color; the higher acid concentrations cleared faster than the $1.5 \mathrm{M} \mathrm{HNO}_{3}$ test. This response is consistent with the literature which states that Reaction 1 , the direct reaction of $\mathrm{NaMnO}_{4}$ with $\mathrm{H}_{2} \mathrm{C}_{2} \mathrm{O}_{4}$, is a slow reaction. ${ }^{[7]}$

Each subsequent aliquot of $\mathrm{NaMnO}_{4}$ cleared faster than the previous addition. The reaction kinetics change because, according to Reactions 2 and 3, which are both fast reactions, the accumulation of Mn(II) in solution facilitates rapid oxidation of $\mathrm{H}_{2} \mathrm{C}_{2} \mathrm{O}_{4}$ by $\mathrm{MnO}_{2}$. Consistent with Reactions 2 and 3, the purple color attributed to $\mathrm{Mn}(\mathrm{VII})$ changes to brown $\left(\mathrm{MnO}_{2}\right)$, and then the solution clears. By about the 15th (out of 21) aliquot, the disappearance of the purple and brown colors occurs in less than five seconds.

The behavior can be understood better from the data in Table 4-1. The data depict the approximate time at which the solution becomes a particular color. The data is arbitrary as the transition from purple to brown contains a mixture of both. A similar point can be made with regard to the brown-to-clear transition as there are periods where the solution color is yellow or beige. Regardless, the effect of the ingrowth of $\mathrm{Mn}(\mathrm{II})$ from Reaction 1 and the prominence of Reactions 2 and 3 in the latter stage of the experiment is unmistakable.

Table 4-1. Times (M:SS) of Solution Color Observations for $1.0 \mathrm{M} \mathrm{HNO}_{3}$ Test

\begin{tabular}{|c|c|c|c|}
\hline Aliquot & Purple & Brown & Clear \\
\hline 1 & $0: 01$ & $3: 30$ & $7: 30$ \\
\hline 6 & $0: 01$ & $0: 35$ & $3: 15$ \\
\hline 11 & $0: 01$ & $0: 10$ & $1: 45$ \\
\hline 16 & n/a & $0: 01$ & $0: 45$ \\
\hline 20 & n/a & $0: 01$ & $0: 25$ \\
\hline 21 & n/a & $0: 01$ & n/a \\
\hline
\end{tabular}

Samples were collected from each test solution after $0,10,15,21$, and 23 aliquots. All were analyzed by IC anion. Aliquots 10, 21, and 23 were analyzed by ICPES. The data are reported in Table 4-2. The calculated initial oxalate ion concentration is $\sim 13,200 \mathrm{mg} / \mathrm{L}(0.15 \mathrm{M})$. 
Table 4-2. Solution Analyses for Oxalate Titration Experiments

\begin{tabular}{|c|c|c|c|c|c|}
\hline $\begin{array}{l}\mathrm{HNO}_{3} \\
(\mathrm{M})\end{array}$ & Aliquot & $\begin{array}{c}\mathrm{C}_{2} \mathrm{O}_{4}{ }^{2-} \\
(\mathrm{mg} / \mathrm{L})^{*}[\mathrm{M}]\end{array}$ & $\begin{array}{c}\mathrm{NO}_{3}^{-} \\
(\mathrm{mg} / \mathrm{L})^{*}[\mathrm{M}]\end{array}$ & $\underset{(\mathrm{mg} / \mathrm{L})^{\#}[\mathbf{M}]}{\operatorname{Mn}}$ & $\begin{array}{c}\mathrm{Na} \\
(\mathrm{mg} / \mathrm{L})^{\#}[\mathrm{M}]\end{array}$ \\
\hline \multirow{5}{*}{1.0} & 0 & $12,500[0.142]$ & $62,300[1.00]$ & --- & --- \\
\hline & 10 & 5930 [0.067] & 61,600 [0.99] & $1690[0.0308]$ & $794[0.0346]$ \\
\hline & 15 & 2510 [0.029] & $61,900[1.00]$ & 2510 [0.0457] & $1150[0.0500]$ \\
\hline & 21 & $<100[0.001]$ & $60,200[0.97]$ & $3540[0.0644]$ & $1650[0.0718]$ \\
\hline & 23 & $<100[0.001]$ & $59,000[0.95]$ & $2990[0.0544]$ & $1760[0.0766]$ \\
\hline \multirow{5}{*}{1.5} & 0 & $13,200[0.150]$ & $93,500[1.51]$ & --- & --- \\
\hline & 10 & $5990[0.068]$ & $91,200[1.47]$ & $1630[0.0297]$ & $<1230[<0.0535]$ \\
\hline & 15 & $2380[0.027]$ & $90,300[1.46]$ & --- & --- \\
\hline & 21 & $<100[0.001]$ & $89,000[1.44]$ & 3170 [0.0577] & $1540[0.0670]$ \\
\hline & 23 & $<100[0.001]$ & $88,600[1.43]$ & $2660[0.0484]$ & $1640[0.0714]$ \\
\hline \multirow{5}{*}{4.0} & 0 & $12,800[0.145]$ & $248,000[4.00]$ & --- & --- \\
\hline & 10 & $5940[0.068]$ & $252,000[4.06]$ & $1620[0.0295]$ & $<1230[<0.0535]$ \\
\hline & 15 & $2290[0.026]$ & $244,000[3.94]$ & --- & --- \\
\hline & 21 & $<100[0.001]$ & $246,000[3.97]$ & $3160[0.0575]$ & $1520[0.0661]$ \\
\hline & 23 & $<100[0.001]$ & $245,000[3.95]$ & $2660[0.0484]$ & $1670[0.0727]$ \\
\hline \multirow{5}{*}{6.0} & 0 & $13,200[0.150]$ & $372,000[6.00]$ & --- & --- \\
\hline & 10 & $5730[0.065]$ & $372,000[6.00]$ & $1620[0.0295]$ & $<1230[<0.0535]$ \\
\hline & 15 & $2240[0.025]$ & $365,000[5.89]$ & --- & --- \\
\hline & 21 & $<100[0.001]$ & $365,000[5.89]$ & $3110[0.0566]$ & $1490[0.0648]$ \\
\hline & 23 & $<100[0.001]$ & $363,000[5.85]$ & $2550[0.0464]$ & $1650[0.0718]$ \\
\hline \multicolumn{6}{|c|}{$\begin{array}{l}\text { * Measured by IC Anion (method uncertainty = 10\%) } \\
{ }^{\#} \text { Measured by ICPES (method uncertainty = 10\%) }\end{array}$} \\
\hline
\end{tabular}

The data enable several conclusions. Analysis of the starting (Aliquot 0) oxalate and nitrate concentrations confirms that the solutions were prepared correctly. Similarly, for the analysis of Mn, calculations indicate that ten aliquots of $3.31 \mathrm{M} \mathrm{NaMnO}_{4}$ into $100 \mathrm{~mL}$ of solution should yield a Mn concentration of $1631 \mathrm{mg} / \mathrm{L}$ (see Table 4-3). The analyses of Na are 105-109\% of what is expected based on a $\mathrm{NaMnO}_{4}$ concentration of $3.31 \mathrm{M}$, but are within the analytical method uncertainty of $10 \%$.

Table 4-3 compares measured versus calculated values for $\mathrm{C}_{2} \mathrm{O}_{4}{ }^{2-}$ and $\mathrm{Mn}$ concentrations. A comparison of the measured versus calculated values for Mn shows that at 10 aliquots, as discussed above, the measured and calculated values are the same. After 21 aliquots, the measured Mn is slightly lower than the calculated value, presumably due to $\mathrm{MnO}_{2}$ precipitation, although the difference is within the analytical method uncertainty. However, after 23 aliquots, the measured Mn decreased and is much lower than the amount added, which is clear evidence that soluble Mn(VII) is being converted to insoluble Mn(IV) according to Reaction 2. 
Table 4-3. Process Behavior Based on Solution Analyses

\begin{tabular}{|c|c|c|c|c|c|c|}
\hline $\begin{array}{c}\mathrm{HNO}_{3} \\
(\mathrm{M})\end{array}$ & Aliquot & $\begin{array}{l}\mathrm{C}_{2} \mathrm{O}_{4}{ }^{2-} \\
(\mathrm{M})^{*}\end{array}$ & $\begin{array}{l}\text { Mn } \\
\text { (M) }\end{array}$ & $\begin{array}{c}\text { Calc Mn } \\
\text { Added (M) }\end{array}$ & $\begin{array}{c}\Delta \mathrm{C}_{2} \mathrm{O}_{4}{ }^{2-} \\
(\mathbf{M})\end{array}$ & $\begin{array}{c}\Delta \mathrm{C}_{2} \mathrm{O}_{4}{ }^{2-} \text { based on } \\
\mathrm{Mn} \text { Added (M) }\end{array}$ \\
\hline \multirow{4}{*}{1.0} & 0 & 0.142 & --- & --- & --- & --- \\
\hline & 10 & 0.067 & 0.0308 & 0.0297 & -0.0747 & -0.0742 \\
\hline & 21 & $<0.001$ & 0.0644 & 0.0617 & -0.141 & -0.154 \\
\hline & 23 & $<0.001$ & 0.0544 & 0.0675 & --- & --- \\
\hline \multirow{4}{*}{1.5} & 0 & 0.150 & --- & --- & $\overline{---}$ & -- \\
\hline & 10 & 0.068 & 0.0297 & 0.0297 & -0.0819 & -0.0742 \\
\hline & 21 & $<0.001$ & 0.0577 & 0.0617 & -0.149 & -0.154 \\
\hline & 23 & $<0.001$ & 0.0484 & 0.0675 & --- & --- \\
\hline \multirow{4}{*}{4.0} & 0 & 0.145 & --- & --- & & \\
\hline & 10 & 0.068 & 0.0295 & 0.0297 & -0.0780 & -0.0742 \\
\hline & 21 & $<0.001$ & 0.0575 & 0.0617 & -0.144 & -0.154 \\
\hline & 23 & $<0.001$ & 0.0484 & 0.0675 & --- & --- \\
\hline \multirow{4}{*}{6.0} & 0 & 0.150 & --- & --- & --- & --- \\
\hline & 10 & 0.065 & 0.0295 & 0.0297 & -0.0849 & -0.0742 \\
\hline & 21 & $<0.001$ & 0.0566 & 0.0617 & -0.149 & -0.154 \\
\hline & 23 & $<0.001$ & 0.0464 & 0.0675 & --- & --- \\
\hline
\end{tabular}

The change in measured $\mathrm{C}_{2} \mathrm{O}_{4}{ }^{2-}$ versus calculated $\mathrm{C}_{2} \mathrm{O}_{4}{ }^{2-}$ suggests that the change in oxalate concentration after 10 aliquots was $105-114 \%$ of the expected amount based on Reactions 1-3 and the amount of Mn added; it was $91-97 \%$ of the theoretical amount after 21 aliquots. A difference of $14 \%$ is outside of the individual method uncertainties of $10 \%$. However, visual observations for all three test solutions indicated that they reached their end points within one aliquot (5\%) of excess $\mathrm{NaMnO}_{4}$. The difference between the measured and calculated concentrations after 10 aliquots might be due to oxalate forming intermediate compounds not measured by IC anion which, nonetheless, consume $\mathrm{Mn}$ (VII) and Mn(IV) as part of Reactions 1 and 3. The literature proposes several pathways for the oxidation of oxalate by permanganate. $^{[7]}$

\subsection{Process Flowsheet Testing}

Process flowsheet testing, in which $\mathrm{NaMnO}_{4}$ solution is pumped continuously into a solution of $\mathrm{HNO}_{3}$ $\mathrm{H}_{2} \mathrm{C}_{2} \mathrm{O}_{4}$, had several objectives. Among these objectives were 1) correlate the observations from titration testing (Section 4.1) with continuous processing, 2) confirm complete oxidation of $\mathrm{C}_{2} \mathrm{O}_{4}{ }^{2-}$ in solution, 3 ) measure gas generation volumes as a function of time, 4) analyze the off gas for hydrogen $\left(\mathrm{H}_{2}\right)$ gas, and 5) establish a protocol for process implementation in HB-Line. Process flowsheet testing also included experiments to determine the quantity of $\mathrm{NaNO}_{2}$ required for digestion of residual $\mathrm{MnO}_{2}$ solids at the conclusion of the $\mathrm{C}_{2} \mathrm{O}_{4}{ }^{2-}$ conversion reaction.

The overall reaction behavior for the process flowsheet tests mirrored those of the titration experiments. The reaction behavior reflected in the data of Table 4-1 described the solution characteristics during continuous $\mathrm{NaMnO}_{4}$ addition. At first, the solution is only purple (except for Test P7). It gradually shifts to a mixture of purple and brown. After about half of the $\mathrm{NaMnO}_{4}$ has been added, the purple associated with new $\mathrm{NaMnO}_{4}$ additions disappears almost instantly. Eventually, the solution ceases to be brown and fluctuates between yellow-beige (when $\mathrm{NaMnO}_{4}$ drops recently entered the reaction vessel) and clear. 
When the $\mathrm{H}_{2} \mathrm{C}_{2} \mathrm{O}_{4}$ reaction end point is reached, the solution quickly turns brown due to the presence of $\mathrm{MnO}_{2}$, which readily settle (Figure 3-2) in the absence of agitation.

\subsubsection{Oxalate Destruction Solution Analyses}

Data analyses in Section 4.1 demonstrated that $\mathrm{C}_{2} \mathrm{O}_{4}{ }^{2-}$ is not present in solution when $\mathrm{MnO}_{2}$ solids form and persist. Because the process flowsheet tests were concerned with measurement of gas volumes, the system was not opened up for sampling at the perceived end point of the $\mathrm{C}_{2} \mathrm{O}_{4}{ }^{2-}$ reaction. Samples were obtained from Tests P1, P2, P3, P6, P7, and P8 after $10 \%$ excess $\mathrm{NaMnO}_{4}$ was added. The analyses are listed in Table 4-4. The analyses demonstrate that $\mathrm{C}_{2} \mathrm{O}_{4}{ }^{2-}$ is reacted to below the method detection limit. The nitrate concentrations are consistent with the solution preparation. The final $\mathrm{Mn}$ and $\mathrm{Na}$ concentrations are comparable to those reported in Table 4-2 after 23 aliquots.

Table 4-4. Solution Concentrations for Process Flowsheet Tests

\begin{tabular}{|c|c|c|c|c|c|c|c|c||}
\hline $\begin{array}{c}\text { Test } \\
\#\end{array}$ & $\begin{array}{c}\mathbf{H}_{2} \mathbf{C}_{\mathbf{2}} \mathbf{O}_{\mathbf{4}} \\
(\mathbf{M})\end{array}$ & $\begin{array}{c}\mathbf{H N O}_{3} \\
(\mathbf{M})\end{array}$ & $\begin{array}{c}\mathbf{C}_{2} \mathbf{O}_{\mathbf{4}}{ }^{2-} \\
(\mathbf{m g} / \mathbf{L})\end{array}$ & $\begin{array}{c}\mathbf{N O}_{3}{ }^{-} \\
(\mathbf{m g} / \mathbf{L})\end{array}$ & $\begin{array}{c}\mathbf{N O}_{2}{ }^{-} \\
(\mathbf{m g} / \mathbf{L})\end{array}$ & $\begin{array}{c}\mathbf{N a M n O}_{\mathbf{4}} \\
(\mathbf{m m o l})\end{array}$ & $\begin{array}{c}\mathbf{M n} \\
(\mathbf{m g} / \mathbf{L})\end{array}$ & $\begin{array}{c}\mathbf{N a} \\
(\mathbf{m g} / \mathbf{L})\end{array}$ \\
\hline P1 & 0.150 & 4.0 & $<100$ & 264,000 & $<100$ & 7.18 & 2370 & 1730 \\
\hline P2 & 0.150 & 1.5 & $<100$ & 94,000 & $<100$ & 7.12 & 2370 & 1660 \\
\hline P3 & 0.150 & 6.0 & $<100$ & 358,000 & $<100$ & 7.35 & 2470 & 1690 \\
\hline P6 & 0.151 & 1.4 & $<100$ & 85,500 & $<100$ & 7.32 & 2030 & 1630 \\
\hline P7 & 0.150 & 1.4 & $<100$ & 88,500 & $<100$ & 7.02 & 2370 & 1770 \\
\hline P8 & 0.150 & 2.4 & $<100$ & 147,000 & $<100$ & 10.3 & 1790 & 1550 \\
\hline
\end{tabular}

With each test, the pump display volumes were noted when the first drop of $\mathrm{NaMnO}_{4}$ was introduced into the reaction and when precipitation of $\mathrm{MnO}_{2}$ occurred and persisted. Consequently, the total mass of $\mathrm{NaMnO}_{4}$ required to completely oxidize $\mathrm{C}_{2} \mathrm{O}_{4}{ }^{2-}$ can be calculated. The data are presented in Table 4-5. Of particular interest is the last column of the table. The data for Tests P1, P2, P3, P4, P5, and P7 are consistently at a $\mathrm{H}_{2} \mathrm{C}_{2} \mathrm{O}_{4}-\mathrm{NaMnO}_{4}$ mole ratio of 2.26-2.37; even Test P6, which had a slight irregularity, is of a similar mole ratio. The amount of $\mathrm{NaMnO}_{4}$ added exceeded the theoretical minimum required since the ratios are slightly less than the stoichiometric value of 2.5. This indicates that the system is slightly past the end point when $\mathrm{MnO}_{2}$ forms and persists.

Table 4-5. $\mathrm{NaMnO}_{4}$ Added to Precipitate $\mathrm{MnO}_{2}$

\begin{tabular}{|c|c|c|c|c|c|c|}
\hline $\begin{array}{l}\text { Test } \\
\text { Order }\end{array}$ & $\begin{array}{c}\text { Test } \\
\# \\
\end{array}$ & $\begin{array}{c}\mathrm{H}_{2} \mathrm{C}_{2} \mathrm{O}_{4} \\
(\mathrm{M}) \\
\end{array}$ & $\begin{array}{l}\mathrm{HNO}_{3} \\
(\mathrm{M})\end{array}$ & $\begin{array}{c}\mathrm{NaMnO}_{4} \\
(\mathrm{M}) \\
\end{array}$ & $\begin{array}{l}\mathrm{NaMnO}_{4} \text { to } \\
\text { Ppt. (mL) }\end{array}$ & $\begin{array}{l}\mathrm{Mol} \mathrm{H}_{2} \mathrm{C}_{2} \mathrm{O}_{4} \text { : } \\
\mathrm{Mol} \mathrm{NaMnO}_{4}\end{array}$ \\
\hline 1 & $\mathrm{P} 1$ & 0.150 & 4.0 & 3.31 & 1.95 & 2.33 \\
\hline 2 & $\mathrm{P} 2$ & 0.150 & 1.5 & 3.31 & 1.93 & 2.35 \\
\hline 3 & P3 & 0.150 & 6.0 & 3.31 & 2.01 & 2.26 \\
\hline 4 & $\mathrm{P} 4$ & 0.150 & 1.4 & 3.31 & 1.91 & 2.37 \\
\hline 5 & P6 & 0.151 & 1.4 & 3.31 & 1.98 & 2.30 \\
\hline 6 & P8 & 0.150 & 2.4 & 3.31 & $2.06^{*}$ & 2.20 \\
\hline 7 & P7 & 0.150 & 1.4 & 3.31 & 1.92 & 2.36 \\
\hline 8 & P5 & 0.150 & 1.4 & 1.65 & 5.79 & 1.57 \\
\hline 9 & P9 & 0.159 & 7.0 & 3.31 & 2.85 & 1.68 \\
\hline
\end{tabular}


The mole ratios for Tests P5 and P9 (Table 4-5) are notably lower. It is believed that there was partial plugging of the discharge side of the $\mathrm{NaMnO}_{4}$ feed line which distorted the actual volume of $\mathrm{NaMnO}_{4}$ fed. The impact of the feed line was particularly noted during Test P9 when there was a period where the flow was temporarily interrupted and noticeably slower thereafter. This behavior is readily correlated with the off gas data presented below. In retrospect, based on the data in Table 4-5 and the off gas data discussed below, Test P5 was impacted by a similar issue. The line clean-out activity with water and air between Tests P5 and P9 was not sufficient.

\subsubsection{Oxalate Destruction Gas Generation}

The complete list of gas generation data is provided in Appendix 9.1. The data are plotted in Figure 4-1. The data are plotted as a function of equivalent $\mathrm{NaMnO}_{4}$ addition rates. What this means is that for Test P4, in which the $\mathrm{NaMnO}_{4}$ feed rate was one-third that of the baseline rate, the pump times in Appendix 9.1 are divided by three to allow a direct comparison with the baseline feed rate. Similarly, for Test P5, in which the $\mathrm{NaMnO}_{4}$ feed concentration was one-half that of the baseline rate, the pump times in Appendix 9.1 are divided by two to allow a direct comparison with the baseline feed concentration.

Several conclusions can be drawn from Figure 4-1. First, Tests P2, P3, P6, P7, and P8 have comparable gas-generation profiles. Test P1 probably would have been similar to those five tests except that a couple of drops from the feed tube got into the reaction vessel during assembly. Consequently, although the gas generation for Test P1 (4.0 $\mathrm{M} \mathrm{HNO}_{3}$ ) appears to begin sooner than Tests P2 (1.5 M) and P3 (6.0 M), this is likely an artifact of the operator technique during the first process flowsheet experiment.

A comparison of Tests P2 and P7 shows little difference in the gas-generation profiles. Test P2 was a baseline experiment at $1.5 \mathrm{M} \mathrm{HNO}_{3}$. Test P7 contained a $9.1 \mathrm{~mL}$ "heel" from Test P4. The premise was that the heel from Test $\mathrm{P} 4$ would contain both $\mathrm{Mn}(\mathrm{II})$ and residual $\mathrm{NaNO}_{2}$. As a result, the presence of the heel would cause Reaction 2 and 3 to occur sooner in Test P7 than in Test P2, and that the difference would be evident in a comparison of the gas-generation profiles. During Test P7, the $\mathrm{NaMnO}_{4}$ added to the reaction vessel turned from purple to brown almost immediately (compared to 2-3 min for Test P2). Also, the gas-generation profile for Test P7 begins to rise about a minute before Test P2. However, the overall gas-generation profiles of the two tests were not significantly different.

It is worth noting within this discussion of the effect of $\mathrm{Mn}(\mathrm{II})$ on gas generation that Test P4 exhibited the fastest initial gas generation rates (until gas bag issues at $\sim 7 \mathrm{~min}$ ). Test P4 was conducted at a $\mathrm{NaMnO}_{4}$ feed rate of one-third the baseline rate. Consequently, there was a three-fold amount of time for the reactions to completely convert oxalate to $\mathrm{CO}_{2}$.

In the earlier discussion associated with Table 4-5, it was noted that Tests P5 and P9 required significantly higher volumes of $\mathrm{NaMnO}_{4}$ feed to react all of the $\mathrm{H}_{2} \mathrm{C}_{2} \mathrm{O}_{4}$ and produce $\mathrm{MnO}_{2}$ solids. The gas-generation data in Figure 4-1 provide additional evidence of a partial line blockage. The data for Test P5 (which was completed just prior to P9) exhibit an initial gas release consistent with the other experiments. However, at about four minutes pump time, the gas generation rate exhibits a reduced generation rate that produces a gas-release profile markedly different from the previous seven experiments. Test P9 exhibits a prolonged delay in gas generation; this delay in gas generation was accompanied by visible evidence of $\mathrm{NaMnO}_{4}$ flow inconsistencies. 


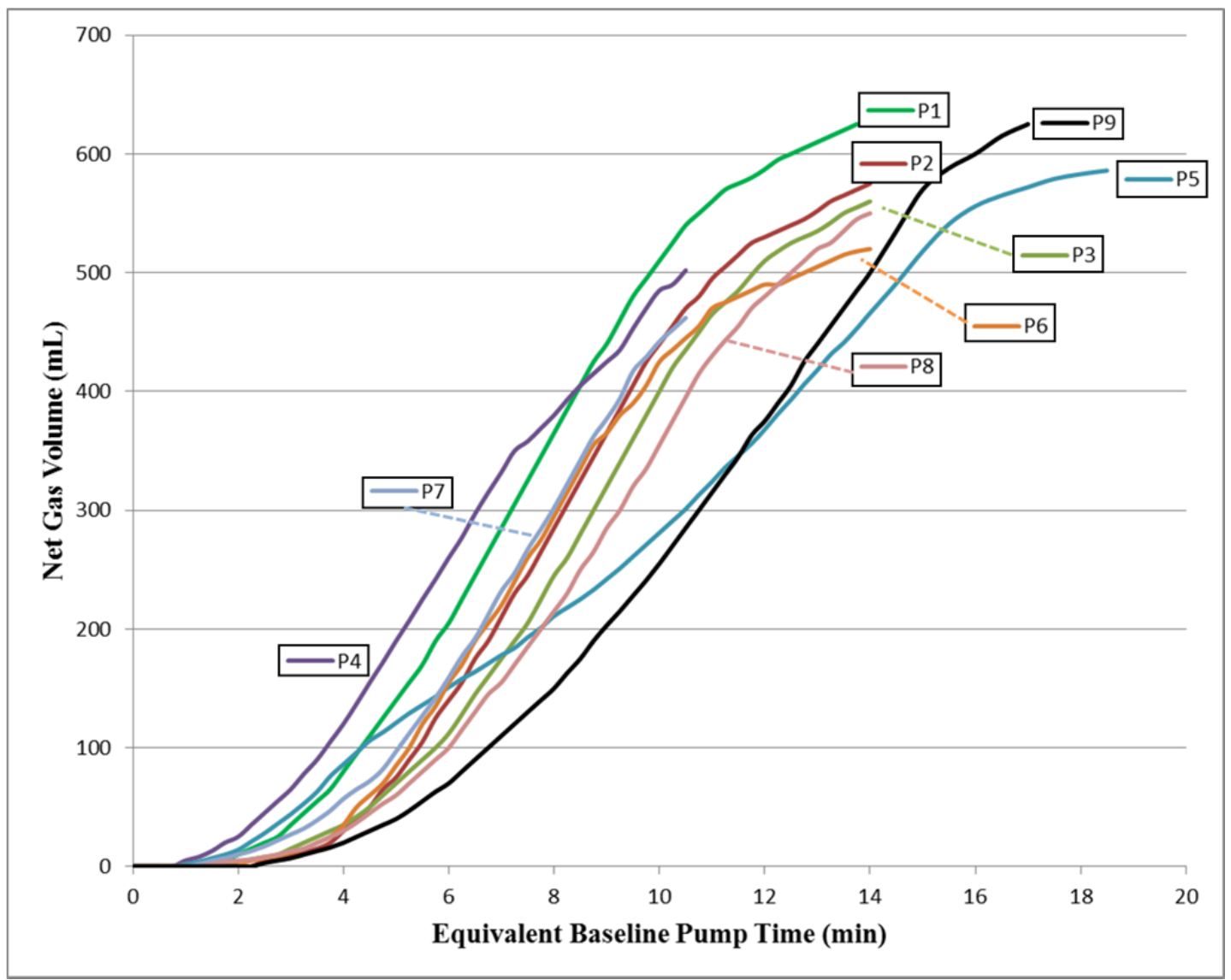

Figure 4-1. Gas Generation Data for Process Flowsheet Tests

The slopes of the gas-generation profiles for the first seven experiments are comparable. The data for gas generation rates across 60-second intervals (equivalent baseline pump time) is graphed in Figure 4-2. The maximum gas generation rate for each of the first six experiments at the baseline $\mathrm{NaMnO}_{4}$ feed rate was $78-80 \mathrm{~mL} / \mathrm{min}$ per $100 \mathrm{~mL}$ of solution. The maximum generation rates occurred at 7-11 min. The highest gas generation rate for a 15-second interval, which occurred only once in Test P7, was $23 \mathrm{~mL}$ (92 mL/min). All other 15-second readings were $20 \mathrm{~mL}$ or lower. The experiments conducted by Hill (which contained oxalic acid, hydrazine, and ascorbic acid) reported typical maximum gas generation rates of $170-250 \mathrm{~mL} / \mathrm{min}$, with the maximum generation rate occurring at $4-7 \mathrm{~min}^{[5]}$

Figure 4-2 again highlights the earlier onset of gas generation associated with Test P4, which had a reduced maximum rate of $73 \mathrm{~mL} / \mathrm{min}$ due to the $\mathrm{NaMnO}_{4}$ feed rate being one-third that of the baseline rate. Figure 4-2 also depicts more clearly the $\mathrm{NaMnO}_{4}$ feed irregularities associated with Tests P5 and P9. For those tests in which gas generation was discontinued prematurely because of issues with the gascollection bag (Tests P4 and P7), the gas generation rates not recorded were lower than the peak rates shown in Figure 4-2. 


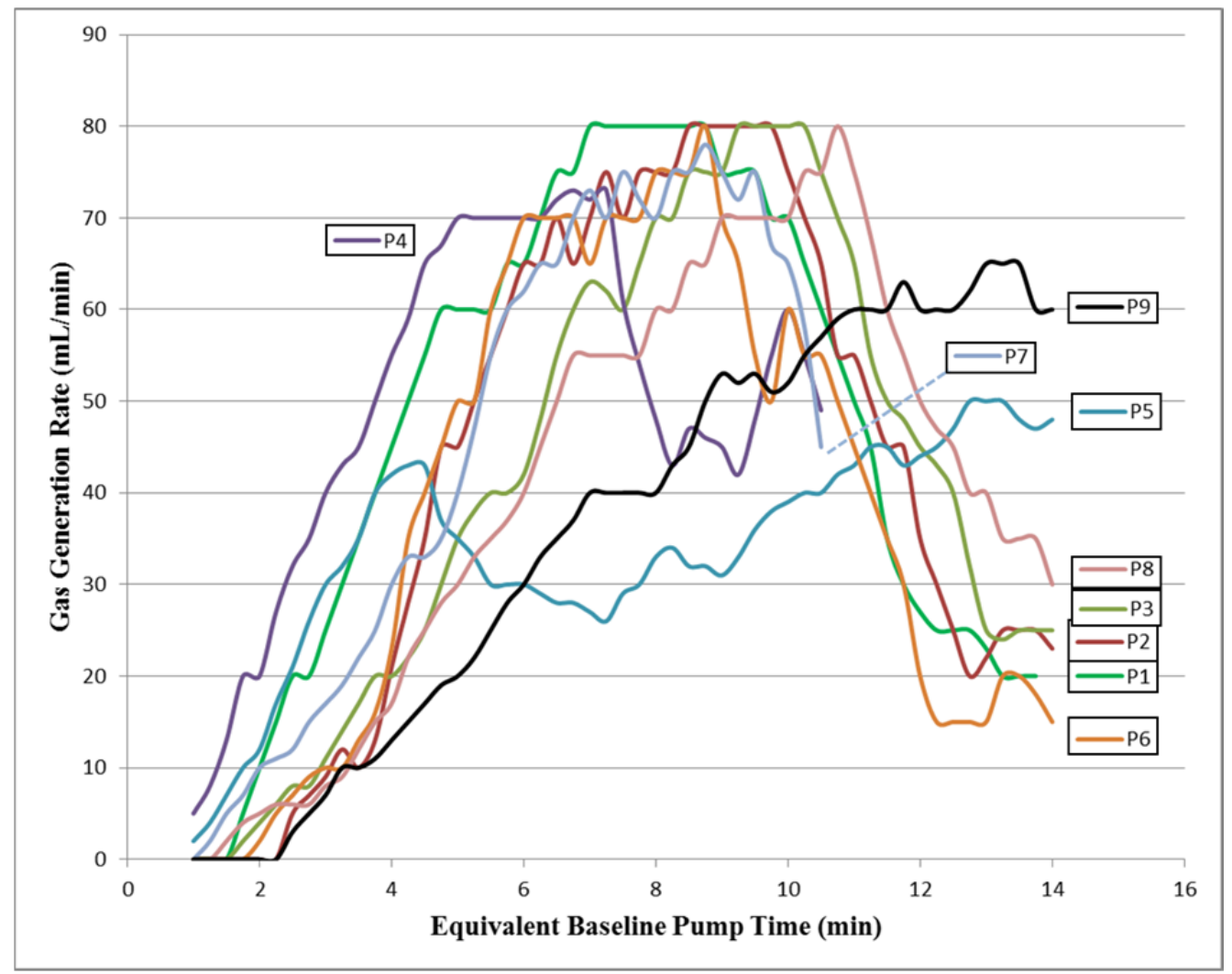

Figure 4-2. Gas Generation Rates for Process Flowsheet Tests

The total volume of gas collected for each test is listed in Table 4-6 along with the expected volume from calculations based on Reactions 1-3. In four of the experiments, gas entrained in the folds of the gas sample bag distorted the total measured gas volume. As the bag expands, gas in the folds of the bag releases out of the liquid reservoir; this causes a net volume decrease in the gas collection vessel. The cause was not clearly understood at first, and the first replacement bag did not correct the issue. For the five experiments without issue, the measured quantity of gas was $93-95 \%$ of the expected volume. Test P1 may have exceeded 95\% had gas collection not been discontinued prematurely. Previous studies by Hill observed similar variability between measured and expected gas volumes. ${ }^{[5]}$

Table 4-6. Total Gas Volumes from Process Flowsheet Testing

\begin{tabular}{|c|c|c|c|c|c|c|c|c|c|}
\hline Test & P1 & P2 & P3 & P4 & P5 & P6 & P7 & P8 & P9 \\
\hline Total (mL) & $625^{\dagger}$ & 640 & 635 & $502^{\#}$ & $591 *$ & $570 *$ & 630 & $462^{\#}$ & 675 \\
\hline Calc (mL) & 672 & 672 & 672 & 672 & 672 & 676 & 672 & 672 & 710 \\
\hline$\%$ of Theory & 93 & 95 & 94 & 74 & 88 & 84 & 94 & 69 & 95 \\
\hline
\end{tabular}

Samples from the gas collection bag were obtained for Tests P1, P2, P3, and P5 and analyzed by GC. Of particular interest was the presence of $\mathrm{H}_{2}$ and $\mathrm{CO}_{2}$. Based on Reactions 1 and 3, there should be an in- 
growth of $\mathrm{CO}_{2}$ and no $\mathrm{H}_{2}$. The GC data are provided in Table 4-7. The method uncertainty for $\mathrm{H}_{2}$, nitrogen $\left(\mathrm{N}_{2}\right)$, and oxygen $\left(\mathrm{O}_{2}\right)$ is $10 \%$; uncertainty for $\mathrm{CO}_{2}$ is $20-25 \%$.

Table 4-7. Gas Analyses from Process Flowsheet Testing

\begin{tabular}{|c|c|c|c|c|c|c|c|}
\hline $\begin{array}{c}\text { Test } \\
\#\end{array}$ & $\begin{array}{c}\mathrm{HNO}_{3} \\
\text { (M) }\end{array}$ & $\begin{array}{c}\mathbf{H}_{2} \\
\text { (vol \%) }\end{array}$ & $\begin{array}{c}\mathrm{N}_{2} \\
(\mathrm{vol} \%)\end{array}$ & $\begin{array}{c}\mathbf{O}_{2} \\
(\mathrm{vol} \%)\end{array}$ & $\begin{array}{c}\mathrm{CO}_{2} \\
\text { (vol \%) }\end{array}$ & $\begin{array}{c}\text { Total } \\
\text { (vol \%) }\end{array}$ & $\mathbf{N}_{2}: \mathbf{O}_{2}$ \\
\hline P1 & 4.0 & $<0.1$ & 56 & 14 & 29 & 99 & 4.0 \\
\hline $\mathrm{P} 2$ & 1.5 & $<0.1$ & 46 & 13 & 25 & 84 & 3.5 \\
\hline P3 & 6.0 & $<0.1$ & 55 & 14 & 25 & 94 & 3.9 \\
\hline P5 & 1.4 & $<0.1$ & 25 & 6.8 & 68 & 99.8 & 3.7 \\
\hline
\end{tabular}

As expected, there was no detectable $\mathrm{H}_{2}$ and air was displaced by $\mathrm{CO}_{2}$. The $\mathrm{N}_{2}: \mathrm{O}_{2}$ ratios for Tests $\mathrm{P} 1, \mathrm{P} 3$, and P5 are consistent with the $\mathrm{N}_{2}: \mathrm{O}_{2}$ ratio for air (3.95). The $\mathrm{N}_{2}: \mathrm{O}_{2}$ ratio and low total for Test P2 suggests that the reported $\mathrm{N}_{2}$ concentration may be low.

Temperature was measured throughout each of the process flowsheet tests. In each case, the temperature gradually increased throughout the test until the $\mathrm{H}_{2} \mathrm{C}_{2} \mathrm{O}_{4}$ oxidation end point was achieved. The initial and maximum temperatures for each test are presented in Table 4-8. It was noted that the onset of temperature increase typically preceded gas generation by about 30-45 seconds. The temperature change for P4 is lower because the experiment used a feed rate of one-third the baseline; Test P5 encountered inconsistencies and disruptions in the $\mathrm{NaMnO}_{4}$ feed rate due to feed line restrictions.

Table 4-8. Initial and Maximum Temperatures during Process Flowsheet Testing

\begin{tabular}{||l|c|c|c|c|c|c|c|c|c||}
\hline \multicolumn{1}{|c|}{ Test } & P1 & P2 & P3 & P4 & P5* & P6 & P7 & P8 & P9 \\
\hline Initial $\mathrm{T}\left({ }^{\circ} \mathrm{C}\right)$ & 20.4 & 20.1 & 20.5 & 21.3 & 21.4 & 21.7 & 21.8 & 23.2 & 25.7 \\
\hline Maximum $\mathrm{T}\left({ }^{\circ} \mathrm{C}\right)$ & 28.1 & 27.6 & 28.8 & 27.0 & 26.6 & 29.2 & 28.7 & 29.8 & 32.5 \\
\hline$\Delta \mathrm{T}\left({ }^{\circ} \mathrm{C}\right)$ & 7.7 & 7.5 & 8.3 & 5.7 & 5.2 & 7.5 & 6.9 & 6.6 & 6.8 \\
\hline
\end{tabular}

\subsubsection{Sodium Nitrite Addition}

At the conclusion of each process flowsheet test, the excess $\mathrm{Mn}$ (present as $\mathrm{MnO}_{2}$ ) was converted to soluble $\mathrm{Mn}(\mathrm{II})$ using $5.65 \mathrm{M} \mathrm{NaNO}_{2}$ solution. Every mole of excess $\mathrm{NaMnO}_{4}$ creates 2.5 moles of $\mathrm{MnO}_{2}$ according to Reaction 2. Dissolution of one mole of $\mathrm{MnO}_{2}$ to soluble $\mathrm{Mn}$ (II) requires one mole of $\mathrm{NaNO}_{2}$. Based on the amount of initial $\mathrm{H}_{2} \mathrm{C}_{2} \mathrm{O}_{4}-2 \mathrm{H}_{2} \mathrm{O}$ and the total $\mathrm{NaMnO}_{4}$ added to the reaction vessel, the required volume of $5.65 \mathrm{M} \mathrm{NaNO}_{2}$ for dissolving excess $\mathrm{MnO}_{2}$ can also be calculated. The calculated quantities and actual volume of $\mathrm{NaNO}_{2}$ added are provided in Table 4-9.

The data show good agreement between the " $\mathrm{NaNO}_{2}$ Required" and " $\mathrm{NaNO}_{2}$ Added to Clear" columns, except for Test P5 and P9 which likely experienced $\mathrm{NaMnO}_{4}$ feed issues. It is worth noting that " $\mathrm{NaNO}_{2}$ Added" is frequently lower than the " $\mathrm{NaNO}_{2}$ Required". The difference may be attributable to the removal of analytical samples. Test P1 having a higher " $\mathrm{NaNO}_{2}$ Added" quantity is likely the result of that test using large incremental additions of $\mathrm{NaNO}_{2}(197.5 \mu \mathrm{L})$ instead of titration from a burette. It is not known why Test P7 does not follow the trend observed in Tests P2, P3, P4, P6, and P8. Minimal amounts of $\mathrm{NO}_{2}$ gas (by Reaction 5) were noted during $\mathrm{NaNO}_{2}$ addition at 1.4-7.0 $\mathrm{M} \mathrm{HNO}_{3}$. 
Table 4-9. Sodium Nitrite Addition Data and Calculations for Process Flowsheet Tests

\begin{tabular}{|c|c|c|c|c|c|c|l||}
\hline $\begin{array}{c}\text { Test } \\
\#\end{array}$ & $\begin{array}{c}\mathbf{C}_{\mathbf{2}} \mathbf{O}_{\mathbf{4}}{ }^{2-} \\
(\mathbf{m m o l})\end{array}$ & $\begin{array}{c}\text { Required } \\
\mathbf{N a M n O} \\
(\mathbf{m m o l})\end{array}$ & $\begin{array}{c}\text { Added }_{\mathbf{N a M n O}} \\
(\mathbf{m m o l})\end{array}$ & $\begin{array}{c}\mathbf{N a N O}_{2} \\
\text { Required } \\
(\mathbf{m m o l})\end{array}$ & $\begin{array}{c}\mathbf{N a N O}_{2} \\
\text { Required } \\
(\boldsymbol{\mu} \mathbf{L})\end{array}$ & $\begin{array}{c}\mathbf{N a N O}_{2} \\
\text { Added to } \\
\mathbf{C l e a r}(\boldsymbol{\mu} \mathbf{L})\end{array}$ & \multicolumn{1}{|c|}{ Note } \\
\hline P1 & 15.02 & 6.01 & 7.18 & 2.93 & 519 & 592.5 & Not clear at $395 \mu \mathrm{L}$ \\
\hline P2 & 15.01 & 6.00 & 7.12 & 2.79 & 493 & 483 & Not clear at $402.5 \mu \mathrm{L}$ \\
\hline P3 & 15.02 & 6.01 & 7.35 & 3.35 & 593 & 546 & Not clear at $468 \mu \mathrm{L}$ \\
\hline P4 & 15.01 & 6.00 & 6.98 & 2.45 & 434 & 400 & --- \\
\hline P5 & 15.01 & 6.00 & 10.28 & 10.69 & 1893 & 1480 & NaMnO $_{4}$ flow issue \\
\hline P6 & 15.08 & 6.03 & 7.32 & 3.21 & 568 & 520 & --- \\
\hline P7 & 15.01 & 6.00 & 7.02 & 2.53 & 448 & 550 & Contains Test P4 heel \\
\hline P8 & 15.01 & 6.01 & 7.51 & 3.77 & 667 & 610 & --- \\
\hline P9 & 15.86 & 6.34 & 10.43 & 10.21 & 1807 & 2720 & NaMnO $_{4}$ flow issue \\
\hline
\end{tabular}

During some of the $\mathrm{NaNO}_{2}$ addition experiments, samples were collected for analysis by IC anion and ICPES. For Tests P1, P2, and P3, samples were obtained at partial $\mathrm{MnO}_{2}$ dissolution, complete $\mathrm{MnO}_{2}$ dissolution, and addition of excess $\mathrm{NaNO}_{2}$. During Tests P4, P6, and P7, samples were collected at the point of complete $\mathrm{MnO}_{2}$ dissolution and after the addition of $25 \%$ excess $\mathrm{NaNO}_{2}$. For Test P8, the only sample collected was after the addition of $25 \%$ excess $\mathrm{NaNO}_{2}$. The data are listed in Table 4-10.

Table 4-10. Solution Data during Sodium Nitrite Addition

\begin{tabular}{|c|c|c|c|c|c|c|}
\hline Test & Condition & $\begin{array}{l}\mathrm{C}_{2} \mathrm{O}_{4}{ }^{2-} \\
(\mathrm{mg} / \mathrm{L})\end{array}$ & $\begin{array}{c}\mathrm{NO}_{3}^{-} \\
(\mathrm{mg} / \mathrm{L})\end{array}$ & $\begin{array}{c}\mathrm{NO}_{2}^{-} \\
(\mathrm{mg} / \mathrm{L})^{*}\end{array}$ & $\begin{array}{c}\mathrm{Mn} \\
(\mathrm{mg} / \mathrm{L})\end{array}$ & $\begin{array}{c}\mathrm{Na} \\
(\mathrm{mg} / \mathrm{L})\end{array}$ \\
\hline \multirow{3}{*}{ P1 } & Partial $\mathrm{MnO}_{2}$ Diss. & $<100$ & 248,000 & $<100$ & 2880 & 1940 \\
\hline & Full $\mathrm{MnO}_{2}$ Diss. & $<100$ & 251,000 & $<100$ & 3780 & 2490 \\
\hline & Excess $\mathrm{NaNO}_{2}$ & $<100$ & 256,000 & $<100$ & 3770 & 2620 \\
\hline \multirow{3}{*}{ P2 } & Partial $\mathrm{MnO}_{2}$ Diss. & $<100$ & 95,900 & $<100$ & 2800 & 1830 \\
\hline & Full $\mathrm{MnO}_{2}$ Diss. & $<100$ & 95,800 & $<100$ & 3690 & 2260 \\
\hline & Excess $\mathrm{NaNO}_{2}$ & $<100$ & 95,000 & $<100$ & 3690 & 2400 \\
\hline \multirow{3}{*}{ P3 } & Partial $\mathrm{MnO}_{2}$ Diss. & $<100$ & 362,000 & $<100$ & 3050 & 1950 \\
\hline & Full $\mathrm{MnO}_{2}$ Diss. & $<100$ & 366,000 & $<100$ & 3710 & 2360 \\
\hline & Excess $\mathrm{NaNO}_{2}$ & $<100$ & 358,000 & $<100$ & 3700 & 2490 \\
\hline \multirow{2}{*}{ P4 } & Full $\mathrm{MnO}_{2}$ Diss. & $<100$ & 87,300 & $<100$ & 3450 & 2110 \\
\hline & $25 \%$ Excess $\mathrm{NaNO}_{2}$ & $<100$ & 87,500 & $<100$ & 3450 & 2240 \\
\hline \multirow{2}{*}{ P6 } & Full $\mathrm{MnO}_{2}$ Diss. & $<100$ & 87,700 & $<100$ & 3580 & 2320 \\
\hline & $25 \%$ Excess $\mathrm{NaNO}_{2}$ & $<100$ & 87,600 & $<100$ & 3580 & 2500 \\
\hline \multirow{2}{*}{ P7 } & Full $\mathrm{MnO}_{2}$ Diss. & $<100$ & 88,400 & $<100$ & 3630 & 2350 \\
\hline & $25 \%$ Excess $\mathrm{NaNO}_{2}$ & $<100$ & 89,600 & $<100$ & 3670 & 2570 \\
\hline P8 & $25 \%$ Excess $\mathrm{NaNO}_{2}$ & $<100$ & 150,000 & $<100$ & 3490 & 2540 \\
\hline
\end{tabular}

The data demonstrate the fundamentals of the $\mathrm{MnO}_{2}$ dissolution step. For each test, the Na concentration increases as $\mathrm{NaNO}_{2}$ is added. Also, the Mn concentrations for Tests P1, P2, and P3 increase from "Partial $\mathrm{MnO}_{2}$ Dissolution" to "Full $\mathrm{MnO}_{2}$ Dissolution" as $\mathrm{MnO}_{2}$ solid is reacted with $\mathrm{NaNO}_{2}$ to form soluble $\mathrm{Mn}(\mathrm{II})$. However, after full $\mathrm{MnO}_{2}$ dissolution, additional $\mathrm{NaNO}_{2}$ does not produce an increase in $\mathrm{Mn}$ 
concentration, as seen in the "Excess $\mathrm{NaNO}_{2}$ " sample. These results confirm that $\mathrm{MnO}_{2}$ dissolution is complete.

\subsection{Precipitator Tank Clean-Out Solution}

Periodic clean-out of the precipitator will create a condition in which plutonium ions, oxalate ions, and potentially plutonium oxalate solids are present. The maximum allowable concentration of $\mathrm{Pu}$ is $60 \mathrm{~g} / \mathrm{L}$ (or $0.25 \mathrm{M}$ ), and the corresponding oxalate concentration is $0.50 \mathrm{M}$. The baseline flowsheet employs 14 $\mathrm{M} \mathrm{HNO}_{3}$ for the clean-out process because of the solubility of $\mathrm{Pu}\left(\mathrm{C}_{2} \mathrm{O}_{4}\right)_{2}$ in strong acid. Testing was completed using $\mathrm{Ce}$ as a simulant for $\mathrm{Pu}$, even though the suitability of $\mathrm{Ce}$ is limited. In $\mathrm{HNO}_{3}$, $\mathrm{Pu}$ has three common valence states - $\mathrm{Pu}(\mathrm{III}), \mathrm{Pu}(\mathrm{IV})$, and $\mathrm{Pu}(\mathrm{VI})$. The electrochemical potential between $\mathrm{Pu}(\mathrm{III})$ and $\mathrm{Pu}(\mathrm{IV})$ is $-0.92 \mathrm{~V}$, between $\mathrm{Pu}(\mathrm{IV})$ and $\mathrm{Pu}(\mathrm{VI})$ is $-1.10 \mathrm{~V}$, and between $\mathrm{Pu}(\mathrm{III})$ and $\mathrm{Pu}(\mathrm{VI})$ is $-1.04 \mathrm{~V}^{[8]}$ Cerium has two common valence states in $\mathrm{HNO}_{3}-\mathrm{Ce}(\mathrm{III})$ and $\mathrm{Ce}(\mathrm{IV})$ - with an electrochemical potential of $-1.72 \mathrm{~V}$ between $\mathrm{Ce}(\mathrm{III})$ and $\mathrm{Ce}(\mathrm{IV}) .{ }^{[9]}$ When the electrochemical potential of a chemical species is more negative than another chemical species in contact with it, the potential exists for the more-negative species to be reduced and the less-negative species to be oxidized. As the difference between the electrochemical potentials of the two species increases, the reaction becomes more favorable.

Prior to evaluating the baseline flowsheet, a determination had to be made regarding the appropriate initial valence state for Ce in testing - $\mathrm{Ce}(\mathrm{III})$ as $\mathrm{Ce}\left(\mathrm{NO}_{3}\right)_{3}$ or $\mathrm{Ce}(\mathrm{IV})$ as $\left(\mathrm{NH}_{4}\right)_{2} \mathrm{Ce}\left(\mathrm{NO}_{3}\right)_{6}$. Into $1.4 \mathrm{M}$ $\mathrm{HNO}_{3}, \mathrm{Ce}(\mathrm{IV})$ was prepared at $0.179 \mathrm{M} \mathrm{Ce}$ and oxalate was $0.394 \mathrm{M}(0.179$ x $2+10 \%$ excess). Cerium(III) was similarly prepared in $1.4 \mathrm{M} \mathrm{HNO}_{3}$ with an equivalent concentration of oxalate $(0.394 \mathrm{M})$ and $\mathrm{Ce}(\mathrm{III})$ at a concentration $(0.238 \mathrm{M})$ to yield an excess oxalate concentration of $10 \%$. At $1.4 \mathrm{M}$ $\mathrm{HNO}_{3}$, both solutions produced visible quantities of cerium-oxalate precipitate (Figure 4-3). Cerium(IV) in $\mathrm{HNO}_{3}$ solution is yellow. It should be noted that when $\mathrm{Ce}(\mathrm{IV})$ solution was combined with $\mathrm{H}_{2} \mathrm{C}_{2} \mathrm{O}_{4}$ solution (Section 3.4) there was a release of colorless gas, suggesting some reaction between $\mathrm{Ce}(\mathrm{IV})$ and $\mathrm{H}_{2} \mathrm{C}_{2} \mathrm{O}_{4}$. The use of $\mathrm{Ce}(\mathrm{IV})$ for the oxidation of organics has been evaluated for the destruction of organic-based wastes. ${ }^{[8]}$ Oxidation of $\mathrm{NH}_{4}{ }^{+}$by $\mathrm{Ce}(\mathrm{IV})$ is not likely because such a reaction would have 1) released brown $\mathrm{NO}_{2}$ gas (the gas was colorless) and 2) required an increased quantity of $\mathrm{NaMnO}_{4}$ for the reaction [the $\mathrm{Ce}(\mathrm{IV})$ test required less $\mathrm{NaMnO}_{4}$ than the $\mathrm{Ce}(\mathrm{III})$ test].

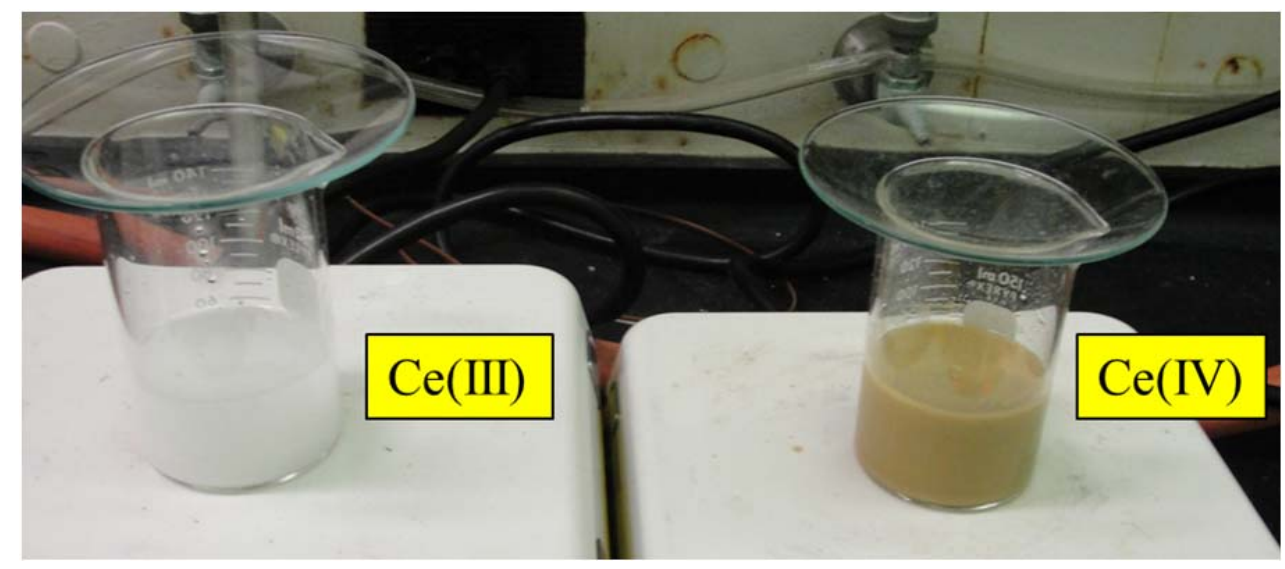

Figure 4-3. $\mathrm{Ce}(\mathrm{III})$ and $\mathrm{Ce}(\mathrm{IV})$ Oxalate in $1.4 \mathrm{M} \mathrm{HNO}_{3}$

Similar to the titration experiments discussed in Section 4.1, both solutions were titrated by pipetting $3.31 \mathrm{M} \mathrm{NaMnO}_{4}$ into them. The volume of each aliquot was $120 \mu \mathrm{L}$, which is theoretically sufficient to react all of the $\mathrm{H}_{2} \mathrm{C}_{2} \mathrm{O}_{4}$ with 20 aliquots. Similar to earlier titration experiments, the $\mathrm{Ce}(\mathrm{III})$ test required 21 aliquots for $\mathrm{MnO}_{2}$ solids to form and persist; the beaker with Ce(IV) required only 16 aliquots, thus 
providing further evidence of reaction between $\mathrm{Ce}(\mathrm{IV})$ and $\mathrm{H}_{2} \mathrm{C}_{2} \mathrm{O}_{4}$. After 15 aliquots, the solution from the $\mathrm{Ce}(\mathrm{IV})$ test was clear and colorless like that of the $\mathrm{Ce}(\mathrm{III})$ test. Consequently, $\mathrm{Ce}(\mathrm{III})$ was selected as the preferred Ce valence state because, similar to $\mathrm{Pu}(\mathrm{III})$ and $\mathrm{Pu}(\mathrm{IV})$, it does not react to oxidize $\mathrm{H}_{2} \mathrm{C}_{2} \mathrm{O}_{4}$. Based on the electrochemical potential of $\mathrm{Pu}(\mathrm{VI})$ being similar to that of $\mathrm{Pu}(\mathrm{III})$ and $\mathrm{Pu}(\mathrm{IV}){ }^{[9]}$ it is expected that $\mathrm{Pu}(\mathrm{VI})$ will not react to oxidize $\mathrm{H}_{2} \mathrm{C}_{2} \mathrm{O}_{4}$.

Three parallel experiments were conducted in $10 \mathrm{M}, 12 \mathrm{M}$, and $14 \mathrm{M} \mathrm{HNO}_{3}$ (Tests C, D, and E of Table 3-3). The Ce and $\mathrm{H}_{2} \mathrm{C}_{2} \mathrm{O}_{4}$ concentrations were similar to the $\mathrm{Ce}(\mathrm{III})$ test above $-0.238 \mathrm{M}$ Ce and $0.394 \mathrm{M}$ $\mathrm{H}_{2} \mathrm{C}_{2} \mathrm{O}_{4}$. When each of the three test solutions was fully prepared, the amount of solids in the $10 \mathrm{M}$ solution was barely visible and there were no solids in either the $12 \mathrm{M}$ or $14 \mathrm{M}$ solutions. The $14 \mathrm{M}$ test solution had a slight yellow tint (Figure 4-4).

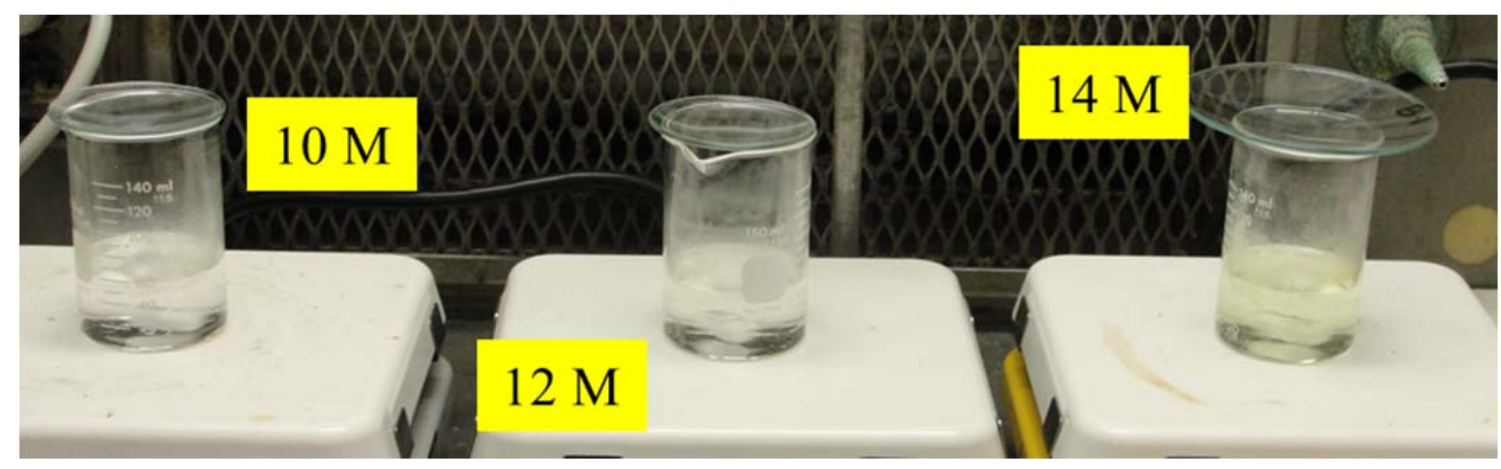

Figure 4-4. Ce(III) and $\mathrm{H}_{2} \mathrm{C}_{2} \mathrm{O}_{4}$ in $10 \mathrm{M}, 12 \mathrm{M}$, and $14 \mathrm{M} \mathrm{HNO}_{3}$

The three solutions were titrated by adding $120 \mu \mathrm{L}$ aliquots of $3.31 \mathrm{M} \mathrm{NaMnO}_{4}$ to each beaker. Based on previous testing, the expected end point was 21 aliquots. However, with the first addition of $\mathrm{NaMnO}_{4}$, there appeared to be an interaction between the Ce and permanganate, especially in $14 \mathrm{M} \mathrm{HNO}_{3}$ (Figure 4-5). The electrochemical potential for $\mathrm{MnO}_{4}{ }^{-}$to $\mathrm{Mn}^{2+}$ is $1.507 \mathrm{~V} .^{[10]}$ Although, by itself, $\mathrm{MnO}_{4}^{-}$ cannot convert $\mathrm{Ce}(\mathrm{III})$ to $\mathrm{Ce}(\mathrm{IV})[1.72 \mathrm{~V}]$, the conversion may be possible in a strong oxidizing acid. Apart from change in coloration, the reaction of $\mathrm{NaMnO}_{4}$ with $\mathrm{H}_{2} \mathrm{C}_{2} \mathrm{O}_{4}$ occurred in a manner reported above.

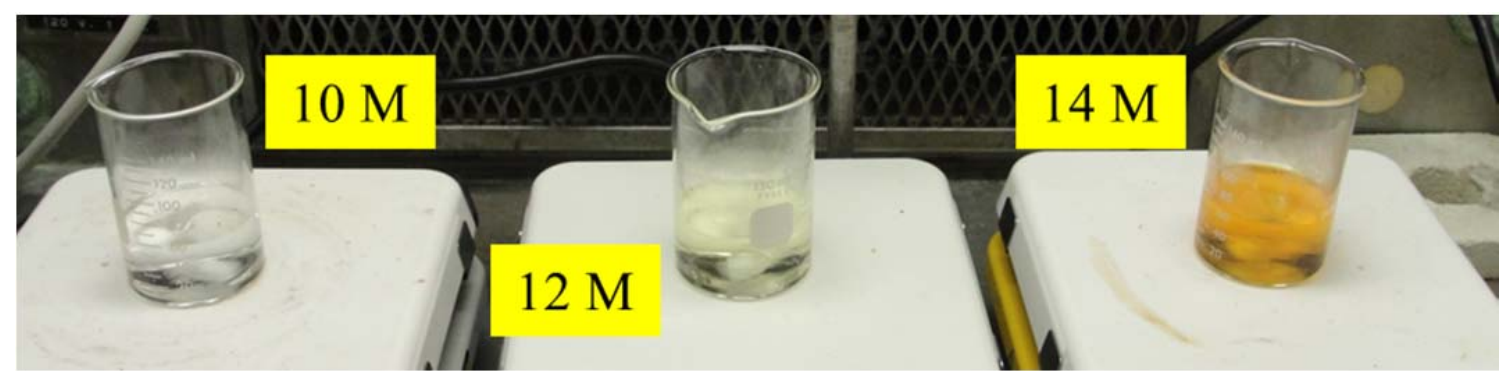

Figure 4-5. Ce(III) and $\mathrm{H}_{2} \mathrm{C}_{2} \mathrm{O}_{4}$ in $10 \mathrm{M}, 12 \mathrm{M}$, and $14 \mathrm{M} \mathrm{HNO}_{3}$ after First $\mathrm{NaMnO}_{4}$ Aliquot

The titration data indicate some interaction between $\mathrm{NaMnO}_{4}$ and $\mathrm{Ce}(\mathrm{III})$ to consume $\mathrm{NaMnO}_{4}$ [presumably resulting in the formation of yellow Ce(IV)]. Instead of requiring 21 aliquots to reach the end point, the $10 \mathrm{M}, 12 \mathrm{M}$, and $14 \mathrm{M}$ solutions required 23, 25, and 28 aliquots, respectively. The interaction can be seen after 21 aliquots (Figure 4-6), just prior to the formation of $\mathrm{MnO}_{2}$ in the $10 \mathrm{M}$ solution. 


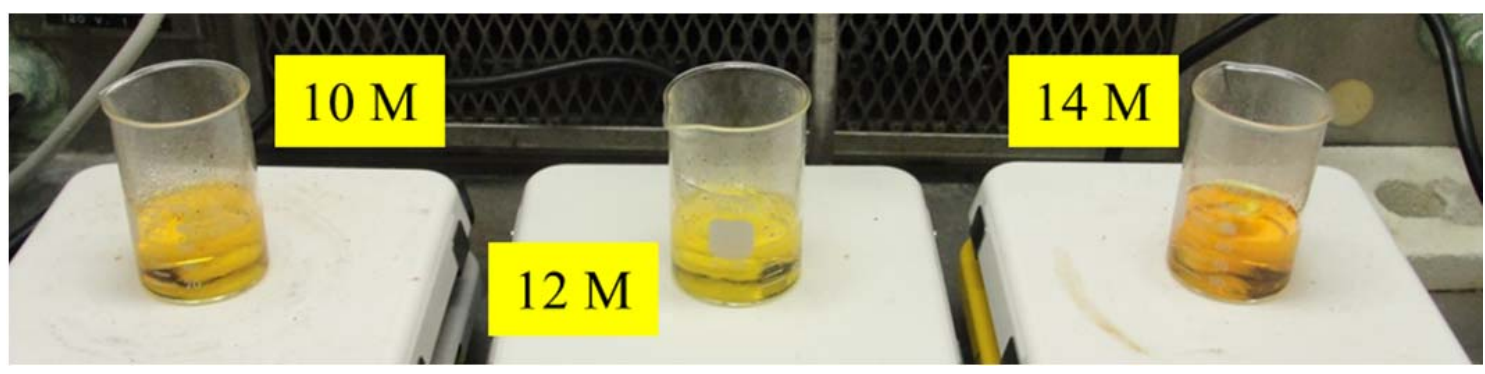

Figure 4-6. $\mathrm{Ce}(\mathrm{III})$ and $\mathrm{H}_{2} \mathrm{C}_{2} \mathrm{O}_{4}$ in $10 \mathrm{M}, 12 \mathrm{M}$, and $14 \mathrm{M} \mathrm{HNO}_{3}$ after $21 \mathrm{NaMnO}_{4}$ Aliquots

The $14 \mathrm{M} \mathrm{HNO}_{3}$ experiment was repeated with one variation. The solution was diluted with an equal volume of $\mathrm{DI} \mathrm{H}_{2} \mathrm{O}$ to $7 \mathrm{M} \mathrm{HNO}_{3}$ (Test F of Table 3-3). When titrated with $3.31 \mathrm{M} \mathrm{NaMnO}_{4}$, the solution required 21 of the $120-\mu \mathrm{L}$ aliquots for $\mathrm{MnO}_{2}$ solids to appear and persist, the same as the experiments described in Section 4.1. The reduced acid concentration either prevented the formation of Ce(IV) or enabled any $\mathrm{Ce}(\mathrm{IV})$ that may have formed to react with $\mathrm{H}_{2} \mathrm{C}_{2} \mathrm{O}_{4}$. Similar to the $1.4 \mathrm{M} \mathrm{HNO}_{3}$ experiments, the solution was clear and colorless prior to the $\mathrm{NaMnO}_{4}$ aliquot that surpassed the end point.

Addition of $\mathrm{NaMnO}_{4}$ to Tests C-F was discontinued when $\mathrm{MnO}_{2}$ solids formed and persisted. These four solutions (with solids) were titrated with $5.65 \mathrm{M} \mathrm{NaNO}_{2}$ until all $\mathrm{MnO}_{2}$ solids disappeared. The $\mathrm{NaNO}_{2}$ was fed with a pipette in $25-\mu \mathrm{L}$ aliquots. Visible $\mathrm{NO}_{2}$ gas (due to $\mathrm{NaNO}_{2}$ reaction with $\mathrm{HNO}_{3}$ ) was observed in Tests C-E, with increased visibility as temperature increased, as described by Reaction 5. However, the amount of $\mathrm{NO}_{2}$ generation did not indicate significant conversion of $\mathrm{NaNO}_{2}$ to $\mathrm{NO}_{2}$.

Tests C-F required $450,575,625$, and $275 \mu \mathrm{L}$ of $5.65 \mathrm{M} \mathrm{NaNO}_{2}$, respectively, to visibly dissolve the $\mathrm{MnO}_{2}$ solids. Calculations compare the amount of $\mathrm{NaNO}_{2}$ added with the expected amount required based on the excess $\mathrm{NaMnO}_{4}$ added relative to the initial quantity of $\mathrm{H}_{2} \mathrm{C}_{2} \mathrm{O}_{4}$ (Table 4-11).

Table 4-11. Sodium Nitrite Addition Data and Calculations for Precipitator Clean-Out Tests

\begin{tabular}{||c|c|c|c|c|c|c|c||}
\hline $\begin{array}{c}\text { Test } \\
\#\end{array}$ & $\begin{array}{c}\mathbf{H N O}_{3} \\
(\mathbf{M})\end{array}$ & $\begin{array}{c}\mathbf{C}_{\mathbf{2}} \mathbf{O}_{\mathbf{4}} \\
(\mathbf{m m o l})\end{array}$ & $\begin{array}{c}\text { Required } \\
\mathbf{N a M n O}_{\mathbf{4}} \\
(\mathbf{m m o l})\end{array}$ & $\begin{array}{c}\text { Added } \\
\mathbf{N a M n O} \\
(\mathbf{m m o l})\end{array}$ & $\begin{array}{c}\mathbf{N a N O}_{2} \\
\text { Required } \\
(\mathbf{m m o l})\end{array}$ & $\begin{array}{c}\mathbf{N a N O}_{2} \\
\text { Required } \\
(\boldsymbol{m} \mathbf{L})\end{array}$ & $\begin{array}{c}\mathbf{N a N O}_{2} \\
\text { Added to } \\
\mathbf{C l e a r}(\boldsymbol{\mu} \mathbf{L})\end{array}$ \\
\hline $\mathrm{C}$ & 10.0 & 19.73 & 7.89 & 9.14 & 3.11 & 551 & 450 \\
\hline $\mathrm{D}$ & 12.0 & 19.73 & 7.89 & 9.93 & 5.10 & 902 & 575 \\
\hline $\mathrm{E}$ & 14.0 & 19.72 & 7.89 & 11.12 & 8.08 & 1431 & 625 \\
\hline $\mathrm{F}$ & 7.0 & 19.73 & 7.89 & 8.34 & 1.12 & 199 & 275 \\
\hline
\end{tabular}

Unlike the data of Table 4-9, where the calculated and actual quantities of $\mathrm{NaNO}_{2}$ corresponded, the amount of $\mathrm{NaNO}_{2}$ added to the tests of Table 4-11 at 10-14 $\mathrm{M} \mathrm{HNO}_{3}$ were notably lower than the calculated amount. Furthermore, the difference between the actual and calculated amounts increased with increasing $\mathrm{HNO}_{3}$ concentration. This means that some of the excess $\mathrm{NaMnO}_{4}$ added did not have to be dissolved with $\mathrm{NaNO}_{2}$, and that fraction increased with increasing acidity. These data provide further evidence that some of the $\mathrm{NaMnO}_{4}$ reacted with Ce(III) to form Ce(IV) and soluble Mn(II) (Figure 4-5) and that the $\mathrm{Ce}(\mathrm{IV})$ was stable in the presence of $\mathrm{H}_{2} \mathrm{C}_{2} \mathrm{O}_{4}$. At $7 \mathrm{M} \mathrm{HNO}_{3}$, the calculated and actual quantities of $\mathrm{NaNO}_{2}$ corresponded, although a somewhat larger $\mathrm{NaNO}_{2}$ excess was needed than in tests at lower $\mathrm{HNO}_{3}$ concentrations. 


\subsection{Conclusions}

\subsection{Oxalate Titration}

The oxidation of $\mathrm{H}_{2} \mathrm{C}_{2} \mathrm{O}_{4}$ in 1.0-7.0 $\mathrm{M} \mathrm{HNO}_{3}$ with $\mathrm{NaMnO}_{4}$ is consistent with Reactions 1-3, as reported in the literature. ${ }^{[7]}$ The initial reaction of $\mathrm{NaMnO}_{4}$ directly with $\mathrm{H}_{2} \mathrm{C}_{2} \mathrm{O}_{4}$ to produce $\mathrm{CO}_{2}, \mathrm{H}_{2} \mathrm{O}$, and $\mathrm{Mn}$ (II) is slow. The in-growth of $\mathrm{Mn}$ (II) enables $\mathrm{NaMnO}_{4}$ to quickly form $\mathrm{MnO}_{2}$, which reacts rapidly with $\mathrm{H}_{2} \mathrm{C}_{2} \mathrm{O}_{4}$. The rate of $\mathrm{H}_{2} \mathrm{C}_{2} \mathrm{O}_{4}$ oxidation increases as the concentration of soluble $\mathrm{Mn}$ (II) increases. The quantity of $\mathrm{NaMnO}_{4}$ required to react all of the $\mathrm{H}_{2} \mathrm{C}_{2} \mathrm{O}_{4}$ can be calculated from the stoichiometry of Reaction 1, which is two moles of $\mathrm{NaMnO}_{4}$ per five moles of $\mathrm{H}_{2} \mathrm{C}_{2} \mathrm{O}_{4}$. It is assumed in these calculations that the concentration of $\mathrm{Pu}$ in the filtrate solution is minimal. As discussed in Section 5.3, Pu in solution may be converted to a higher valence state and consume $\mathrm{NaMnO}_{4}$, with increasing likelihood at higher $\mathrm{HNO}_{3}$ concentration.

When all of the $\mathrm{H}_{2} \mathrm{C}_{2} \mathrm{O}_{4}$ has been converted to $\mathrm{CO}_{2}$, excess $\mathrm{NaMnO}_{4}$ reacts rapidly with $\mathrm{Mn}$ (II) to form brown $\mathrm{MnO}_{2}$ solids according to Reaction 2. The presence of $\mathrm{MnO}_{2}$ solids (not excess permanganate) indicates that the end point of the $\mathrm{H}_{2} \mathrm{C}_{2} \mathrm{O}_{4}$ oxidation reaction has been achieved. The accumulation of $\mathrm{MnO}_{2}$ solids upon addition of $\mathrm{NaMnO}_{4}$ will continue until all $\mathrm{Mn}$ (II) is consumed. Only after all $\mathrm{Mn}$ (II) has been reacted with $\mathrm{NaMnO}_{4}$ to form $\mathrm{MnO}_{2}$ solids will there be detectable $\mathrm{MnO}_{4}{ }^{-}$in solution.

The data show that as $\mathrm{Mn}$ is added as $\mathrm{NaMnO}_{4}$ that the $\mathrm{Na}$ and $\mathrm{Mn}$ concentrations increase while the $\mathrm{C}_{2} \mathrm{O}_{4}{ }^{2-}$ concentration decreases. However, once the $\mathrm{C}_{2} \mathrm{O}_{4}{ }^{2-}$ is below detectable limits, the addition of $\mathrm{NaMnO}_{4}$ caused the $\mathrm{Na}$ concentration to continue to increase while the soluble $\mathrm{Mn}$ concentration decreased (from the formation of $\mathrm{MnO}_{2}$ solids).

\subsection{Process Flowsheet Testing}

Process flowsheet testing confirmed that the reaction behavior and chemical ratios demonstrated during oxalate titration testing are applicable during conditions of continuous $\mathrm{NaMnO}_{4}$ feeding. In seven experiments ranging from $1.4 \mathrm{M}$ to $6.0 \mathrm{M} \mathrm{HNO}_{3}$, the system behavior was consistent with Reactions 1-3. Initial consumption of $\mathrm{NaMnO}_{4}$ was slow due to Reaction 1. Once $\mathrm{Mn}$ (II) accumulated in solution, the overall reaction rate accelerated via Reactions 2 and 3. Throughout testing, $\mathrm{MnO}_{2}$ solids did not persist in the reaction vessel until all $\mathrm{H}_{2} \mathrm{C}_{2} \mathrm{O}_{4}$ was oxidized to $\mathrm{CO}_{2}$.

Gas samples collected from four experiments showed less-than-detectable concentrations of $\mathrm{H}_{2}$ gas. In each test, the gas contained air diluted with $\mathrm{CO}_{2}$ released from the oxidation of $\mathrm{H}_{2} \mathrm{C}_{2} \mathrm{O}_{4}$. Using HB-Line baseline flowsheet feed rates for $\mathrm{NaMnO}_{4}\left(5.46 \mathrm{~L} / \mathrm{h}\right.$ of $\left.3.83 \mathrm{M} \mathrm{NaMnO}_{4}\right)$, the maximum gas generation rate per liter of reaction solution was consistently $750-800 \mathrm{~mL} / \mathrm{min}$; this generation rate is less than half the rate of the previous flowsheet. ${ }^{[5]}$ A single 15-second rate of $230 \mathrm{~mL}$ per liter of solution was observed, or $920 \mathrm{~mL} / \mathrm{min}$. For experiments without issues during gas collection, the quantity of gas collected was 94-95\% of the theoretical value. The gas generation rate was not a function of $\mathrm{HNO}_{3}$ concentration.

The presence of $\mathrm{MnO}_{2}$ solids, which form because of the addition of excess $\mathrm{NaMnO}_{4}$ in the oxidation of $\mathrm{H}_{2} \mathrm{C}_{2} \mathrm{O}_{4}$, is undesirable. Therefore, these solids are dissolved through the addition of $\mathrm{NaNO}_{2}$ solution. Experimentation confirmed that the quantity of $\mathrm{NaNO}_{2}$ required to dissolve $\mathrm{MnO}_{2}$ solids can be accurately calculated from the amount of excess $\mathrm{NaMnO}_{4}$ added (present as $\mathrm{MnO}_{2}$ solids). Experimental data show good agreement between theoretical and actual $\mathrm{NaNO}_{2}$ addition quantities. This applies only to solutions with minimal concentrations of Pu in solution. As discussed in Section 5.3, Pu in solution may be converted to a higher valence state and consume $\mathrm{NaMnO}_{4}$, thereby reducing the amount of $\mathrm{NaNO}_{2}$ required when compared to the calculated value. 


\subsection{Precipitator Tank Clean-Out Solution}

The addition of $\mathrm{Ce}$ as a surrogate for $\mathrm{Pu}$ does not alter the fundamental $\mathrm{H}_{2} \mathrm{C}_{2} \mathrm{O}_{4}$ oxidation chemistry described in Section 2.1. However, the presence of Ce does require additional $\mathrm{NaMnO}_{4}$ in $10-14 \mathrm{M}$ $\mathrm{HNO}_{3}$ due to oxidation of $\mathrm{C}_{2} \mathrm{O}_{4}{ }^{2-}$ and $\mathrm{Ce}(\mathrm{III})$ to $\mathrm{Ce}(\mathrm{IV})$ by $\mathrm{MnO}_{4}{ }^{-} / \mathrm{MnO}_{2}$. Cerium(IV) was not stable in 1.4-7.0 $\mathrm{M} \mathrm{HNO}_{3}$. Therefore, the presence of $\mathrm{Ce}(\mathrm{III})$ at 1.4-7.0 $\mathrm{M}$ did not result in an increase in the amount of $\mathrm{NaMnO}_{4}$ required above that needed to oxidize $\mathrm{C}_{2} \mathrm{O}_{4}{ }^{2-}$. At $1.4 \mathrm{M} \mathrm{HNO}_{3}$, $\mathrm{Ce}(\mathrm{IV})$ reacted with $\mathrm{C}_{2} \mathrm{O}_{4}{ }^{2-}$ to reduce the volume of $\mathrm{NaMnO}_{4}$ required to consume the $\mathrm{C}_{2} \mathrm{O}_{4}{ }^{2-}$. In the case of Ce, the appropriate approach for handling a precipitator clean-out operation would be to clean out with $14 \mathrm{M}$ $\mathrm{HNO}_{3}$ and then dilute the acid to 1.4-7 $\mathrm{M}$ prior to oxidizing the $\mathrm{C}_{2} \mathrm{O}_{4}{ }^{2-}$ with $\mathrm{NaMnO}_{4}$.

Although the behavior of Ce offers an indication of how the presence of Pu will affect the process during the precipitator clean-out operation, there should be significant differences. The difference is attributed to the electrochemical potential of $\mathrm{Ce}(\mathrm{III})-\mathrm{Ce}(\mathrm{IV})$ compared to that of $\mathrm{Pu}(\mathrm{III})-\mathrm{Pu}(\mathrm{IV})-\mathrm{Pu}(\mathrm{VI})$ and $\mathrm{Mn}(\mathrm{II})$ $\mathrm{Mn}(\mathrm{IV})-\mathrm{Mn}(\mathrm{VII})$. The electrochemical potential of the Mn(II)-Mn(VII) couple is $1.51 \mathrm{~V}$ and the potential for the $\mathrm{Mn}(\mathrm{II})-\mathrm{Mn}(\mathrm{IV})$ couple is $1.22 \mathrm{~V}^{[10]}$ It would appear that the electrochemical potential of the $\mathrm{Ce}(\mathrm{III})-\mathrm{Ce}(\mathrm{IV})$ couple is sufficiently high $(1.72 \mathrm{~V})$ to preclude $\mathrm{Mn}(\mathrm{IV})$ or $\mathrm{Mn}(\mathrm{VII})$ from reacting with $\mathrm{Ce}(\mathrm{III})$ to form $\mathrm{Ce}(\mathrm{IV})$. Such was the case in 1.4-7.0 $\mathrm{M} \mathrm{HNO}_{3}$, but in a strong oxidizing acid (10-14 $\mathrm{M}$ $\mathrm{HNO}_{3}$ ), the $\mathrm{NaMnO}_{4}$ reacted with $\mathrm{Ce}(\mathrm{III})$ to form $\mathrm{Ce}(\mathrm{IV})$.

The $\mathrm{Pu}(\mathrm{III})-\mathrm{Pu}(\mathrm{VI})$ couple $(1.04 \mathrm{~V})$ and $\mathrm{Pu}(\mathrm{IV})-\mathrm{Pu}(\mathrm{VI})$ couple $(1.10 \mathrm{~V})$ have significantly lower electrochemical potential than the Ce(III)-Ce(IV) couple. ${ }^{[9]}$ Furthermore, the potentials for the Pu(III)$\mathrm{Pu}(\mathrm{VI})$ and $\mathrm{Pu}(\mathrm{IV})-\mathrm{Pu}(\mathrm{VI})$ couples are lower than the $\mathrm{Mn}(\mathrm{II})-\mathrm{Mn}(\mathrm{IV})$ and $\mathrm{Mn}(\mathrm{II})-\mathrm{Mn}(\mathrm{VII})$ couples. Consequently, it is expected that $\mathrm{Mn}(\mathrm{IV})$ and $\mathrm{Mn}(\mathrm{VII})$ will react with $\mathrm{Pu}(\mathrm{III})$ and $\mathrm{Pu}(\mathrm{IV})$ to form $\mathrm{Pu}(\mathrm{VI})$, and consume excess $\mathrm{NaMnO}_{4}$ to accomplish this oxidation of Pu. Once oxidized, it is expected that the $\mathrm{Pu}(\mathrm{VI})$ will not react with $\mathrm{C}_{2} \mathrm{O}_{4}{ }^{2-}$ the way $\mathrm{Ce}(\mathrm{IV})$ did in $1.4 \mathrm{M} \mathrm{HNO}_{3}$. The basis for this conclusion is that the electrochemical potential for the $\mathrm{Pu}(\mathrm{III}) \mathrm{Pu}(\mathrm{IV})$ couple (which is $0.92 \mathrm{~V}$ ) is similar to that of the $\mathrm{Pu}(\mathrm{III})-\mathrm{Pu}(\mathrm{VI})$ and $\mathrm{Pu}(\mathrm{IV})-\mathrm{Pu}(\mathrm{VI})$ couples. Since $\mathrm{Pu}(\mathrm{IV})$ does not have sufficient potential to oxidize $\mathrm{C}_{2} \mathrm{O}_{4}{ }^{2-}$, it is probable that $\mathrm{Pu}(\mathrm{VI})$ will not oxidize $\mathrm{C}_{2} \mathrm{O}_{4}{ }^{2-}$.

The literature indicates that both $\mathrm{Mn}(\mathrm{VII})$ and $\mathrm{Mn}(\mathrm{IV})$ react with $\mathrm{Pu}(\mathrm{IV})$ in $\mathrm{HNO}_{3}$ to produce $\mathrm{Pu}(\mathrm{VI}) .{ }^{[9]}$ The reaction of $\mathrm{Mn}(\mathrm{VII})$ with $\mathrm{Pu}(\mathrm{IV})$ in $1 \mathrm{M} \mathrm{HNO}_{3}$ is listed with a $\mathrm{t}_{1 / 2}$ of $50 \mathrm{~min}$. The reaction of $\mathrm{Mn}(\mathrm{IV})$ with $\mathrm{Pu}(\mathrm{IV})$ in $5 \mathrm{M} \mathrm{HNO}_{3}$ is identified as "slow". This suggests that the reaction to convert $\mathrm{Pu}(\mathrm{IV})$ to $\mathrm{Pu}(\mathrm{VI})$ is considerably slower than the $\mathrm{C}_{2} \mathrm{O}_{4}{ }^{2-}$ oxidation reaction, especially in the presence of soluble $\mathrm{Mn}(\mathrm{II})$, according to Reaction 2. The data in the literature also suggest that the reaction of $\mathrm{C}_{2} \mathrm{O}_{4}{ }^{2-}$ will occur continuously with the addition of $\mathrm{NaMnO}_{4}$, and that when all $\mathrm{C}_{2} \mathrm{O}_{4}{ }^{2-}$ has been consumed, excess $\mathrm{NaMnO}_{4}$ will be converted rapidly to $\mathrm{MnO}_{2}$ solids. The $\mathrm{MnO}_{2}$ reaction with $\mathrm{Pu}(\mathrm{IV})$ is "slow". Consequently, the end point of the $\mathrm{C}_{2} \mathrm{O}_{4}{ }^{2-}$ oxidation reaction should be identifiable by the presence of $\mathrm{MnO}_{2}$ solids.

Just as the reactions with Ce indicate a benefit from reducing the $\mathrm{HNO}_{3}$ concentration from $14 \mathrm{M}$ to $7 \mathrm{M}$ prior to oxidizing the $\mathrm{C}_{2} \mathrm{O}_{4}{ }^{2-}$, a similar benefit is expected where $\mathrm{Pu}$ is present instead of Ce. Therefore, the $\mathrm{Pu}\left(\mathrm{C}_{2} \mathrm{O}_{4}\right)_{2}$ clean-out operation should be performed in $14 \mathrm{M} \mathrm{HNO}_{3}$, and the resulting solution diluted to 1.4-7 $\mathrm{M} \mathrm{HNO}_{3}$ prior to addition of $\mathrm{NaMnO}_{4}$ to oxidize $\mathrm{C}_{2} \mathrm{O}_{4}{ }^{2-}$.

It should be noted that the magnitude of the impact of $\mathrm{Pu}$ will be proportional to its concentration. Consequently, in a series of precipitator clean-out operations with decreasing concentrations of $\mathrm{Pu}\left(\mathrm{C}_{2} \mathrm{O}_{4}\right)_{2}$, the first cycle will likely be the only cycle requiring a significant volume of $\mathrm{NaMnO}_{4}$. Subsequent cycles are expected to have relatively low $\mathrm{Pu}$ and $\mathrm{C}_{2} \mathrm{O}_{4}{ }^{2-}$ concentrations. 


\subsection{Recommendations}

\subsection{Baseline Process Flowsheet}

SRNL verified that the nominal baseline $\mathrm{NaMnO}_{4}$ addition rate of $5.46 \mathrm{~L} / \mathrm{h}$ of $3.83 \mathrm{M} \mathrm{NaMnO}_{4}$ is valid for this aspect of the flowsheet, or $0.35 \mathrm{~mol} \mathrm{NaMnO} / \mathrm{min}$. This $\mathrm{NaMnO}_{4}$ addition rate, because of the different contents of the filtrate tank, will yield a maximum gas-generation rate of one-third to one-half as much as the previous flowsheet which included the oxidation of hydrazine and ascorbic acid. If a moredilute solution of $\mathrm{NaMnO}_{4}$ is used, a corresponding increase in flow rate is acceptable.

Per liter of filtrate solution, assuming a flowsheet of $0.1 \mathrm{M}$ excess $\mathrm{H}_{2} \mathrm{C}_{2} \mathrm{O}_{4}, 0.044 \mathrm{~mol}$ of $\mathrm{NaMnO}_{4}$ should be added to convert the $\mathrm{H}_{2} \mathrm{C}_{2} \mathrm{O}_{4}$ to $\mathrm{CO}_{2}$ and $\mathrm{H}_{2} \mathrm{O}$ (or $11.5 \mathrm{~mL}$ of $3.83 \mathrm{M} \mathrm{NaMnO}_{4}$ per liter of filtrate). This will provide $10 \%$ molar (theoretical) excess of $\mathrm{NaMnO}_{4}$. The amount of residual $\mathrm{Pu}$ in the filtrate solution does not significantly affect the quantity of $\mathrm{NaMnO}_{4}$ that should be added. The excess $\mathrm{NaMnO}_{4}$ will react with any $\mathrm{Mn}(\mathrm{II})$ in solution to form $\mathrm{MnO}_{2}$ solids - the permanganate is reduced to $\mathrm{MnO}_{2}$ while the $\mathrm{Mn}$ (II) is oxidized to $\mathrm{MnO}_{2}$. The addition of $0.044 \mathrm{~mol}$ of $\mathrm{NaMnO}_{4}$ per liter of filtrate solution may be scaled linearly to any oxalate concentrations less than $0.2 \mathrm{M}$. The amount of $\mathrm{NaMnO}_{4}$ addition can be calculated as $0.44 \mathrm{~mol}$ of $\mathrm{NaMnO}_{4}$ per $1.0 \mathrm{~mol}$ of oxalate; this results in a $10 \%$ molar excess of $\mathrm{NaMnO}_{4}$. Sample at least three minutes after $\mathrm{NaMnO}_{4}$ addition is complete. If brown solids are present, analyze the solution by IC anion to verify that $\mathrm{C}_{2} \mathrm{O}_{4}{ }^{2-}$ is less than detectable.

Following the addition of $\mathrm{NaMnO}_{4}$, the excess, which will be present as $\mathrm{MnO}_{2}$ solids, is dissolved by the addition of $\mathrm{NaNO}_{2}$ solution. The nominal baseline $\mathrm{NaNO}_{2}$ addition rate of $7.2 \mathrm{~L} / \mathrm{h}$ of $5.65 \mathrm{M} \mathrm{NaNO}_{2}$ is valid for this aspect of the flowsheet. Per liter of solution, to react the 0.004 mol of excess $\mathrm{NaMnO}_{4}$ [present as $0.01 \mathrm{~mol}$ of $\mathrm{MnO}_{2}$ from its reaction with $0.006 \mathrm{~mol} \mathrm{Mn}(\mathrm{II})$ ], at least $0.0125 \mathrm{~mol} \mathrm{NaNO}_{2}$ should be added to convert $\mathrm{MnO}_{2}$ to soluble $\mathrm{Mn}$ (II) [or $2.2 \mathrm{~mL}$ of $5.65 \mathrm{M} \mathrm{NaNO}_{2}$ ]. This will provide $25 \%$ molar excess of $\mathrm{NaNO}_{2}$. The excess $\mathrm{NaNO}_{2}$ can potentially react with $\mathrm{HNO}_{3}$ per Reaction 5 to produce $\mathrm{NO}_{2}$ and $\mathrm{NO}$ gases. Although very little $\mathrm{NOx}$ generation was observed, based on the total quantity of $\mathrm{NaNO}_{2}$, the excess will produce a maximum of 0.2 moles of $\mathrm{NO}_{x}$ per mole of $\mathrm{NaNO}_{2}$ added.

\subsection{Precipitator Clean-Out Operations}

During precipitator clean-out operations, it is expected that $\mathrm{Pu}$ and $\mathrm{C}_{2} \mathrm{O}_{4}{ }^{2-}$ will be soluble, although the presence of $\mathrm{Pu}\left(\mathrm{C}_{2} \mathrm{O}_{4}\right)_{2}$ solids does not change the method or amounts. The quantities of $\mathrm{NaMnO}_{4}$ and $\mathrm{NaNO}_{2}$ recommended are based on $100 \mathrm{~g}$ of Pu present as $173.6 \mathrm{~g}$ of dissolved $\mathrm{Pu}\left(\mathrm{C}_{2} \mathrm{O}_{4}\right)_{2}$. It is assumed that $\mathrm{NaMnO}_{4}$ will be consumed principally by the oxidation of $\mathrm{C}_{2} \mathrm{O}_{4}{ }^{2-}$ and only minor amounts by the conversion of $\mathrm{Pu}(\mathrm{IV})$ to $\mathrm{Pu}(\mathrm{VI})$. The addition of $25 \%$ excess is recommended to compensate for the $\mathrm{Pu}(\mathrm{IV})-\mathrm{Pu}(\mathrm{VI})$ couple.

The precipitator clean-out should continue to be performed using $14 \mathrm{M} \mathrm{HNO}_{3}$. As discussed above, when the clean-out operation is complete, the resulting solution should be diluted with $\mathrm{H}_{2} \mathrm{O}$ to 1.4-7 $\mathrm{M} \mathrm{HNO}_{3}$ to potentially suppress the $\mathrm{Pu}(\mathrm{IV})$ oxidation reaction. Per $100 \mathrm{~g}$ of $\mathrm{Pu}$ expected in the precipitator or measured in the filtrate tank, add at least $0.42 \mathrm{~mol}$ of $\mathrm{NaMnO}_{4}$ (or $110 \mathrm{~mL}$ of $3.83 \mathrm{M} \mathrm{NaMnO}_{4}$ ) at the baseline flow rate of $0.35 \mathrm{~mol} \mathrm{NaMnO}_{4} / \mathrm{min}$. Sample after three minutes for brown $\mathrm{MnO}_{2}$ solids. If brown solids are present, analyze the solution by IC anion to verify that $\mathrm{C}_{2} \mathrm{O}_{4}{ }^{2-}$ is less than detectable.

If there is uncertainty regarding whether the solids present in a sample are $\mathrm{MnO}_{2}$ or Pu-oxalate, the uncertainty can be removed by combining the sample with a solution that contains a large excess of $\mathrm{NaNO}_{2}$ in 1-7 $\mathrm{M} \mathrm{HNO}_{3}$ and stirring the combined solution for 3-5 minutes. If the solids are $\mathrm{MnO}_{2}$, they will dissolve. If the solids are $\mathrm{Pu}$ oxalate, they will remain. A comparison of $\mathrm{MnO}_{2}$ solids and $\mathrm{Pu}(\mathrm{IV}$ ) oxalate solids is shown in Figure 6-1. 

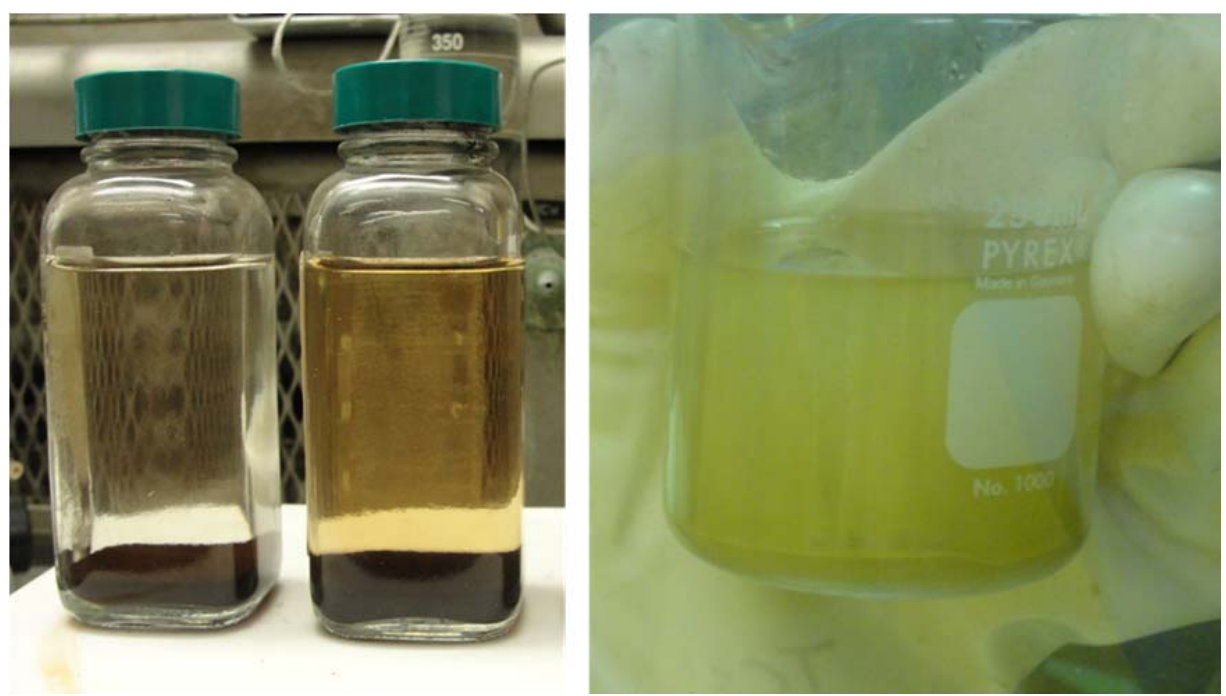

Figure 6-1. Comparison of $\mathrm{MnO}_{2}$ Solids (left) and $\mathrm{Pu}(\mathrm{IV})$ Oxalate Solids (right)

Assuming that the residual solids in the sample were $\mathrm{MnO}_{2}$, the resulting solution in the HB-Line process vessel, with a nominal excess $\mathrm{NaMnO}_{4}$ of 0.084 mol per $100 \mathrm{~g} \mathrm{Pu}$, is reacted with $\mathrm{NaNO}_{2}$ to dissolve any residual $\mathrm{MnO}_{2}$ solids. Dissolution of the $\mathrm{MnO}_{2}$ solids will require $0.21 \mathrm{~mol} \mathrm{NaNO}_{2}$ (or $37 \mathrm{~mL}$ of $5.65 \mathrm{M}$ $\mathrm{NaNO}_{2}$ ) per $100 \mathrm{~g} \mathrm{Pu}$. Allowing for at least 33\% excess, it is recommended that at least $0.28 \mathrm{~mol} \mathrm{NaNO}_{2}$ (or $50 \mathrm{~mL}$ of $5.65 \mathrm{M} \mathrm{NaNO}_{2}$ ) be added per $100 \mathrm{~g}$ Pu to completely dissolve the $\mathrm{MnO}_{2}$ solids.

For the precipitator clean-out operation, it is recommended that minimum quantities of $\mathrm{NaMnO}_{4}$ and $\mathrm{NaNO}_{2}$ added correspond to an assumed quantity of $50 \mathrm{~g} \mathrm{Pu}$ as $\mathrm{Pu}\left(\mathrm{C}_{2} \mathrm{O}_{4}\right)_{2}$. If analyses indicate that 50 or fewer grams of $\mathrm{Pu}$ remain in the precipitator, assume the presence of $50 \mathrm{~g}$. The flowsheet would entail adding at least $0.21 \mathrm{~mol}$ of $\mathrm{NaMnO}_{4}$ (or $55 \mathrm{~mL}$ of $3.83 \mathrm{M} \mathrm{NaMnO}_{4}$ ) for $\mathrm{C}_{2} \mathrm{O}_{4}{ }^{2-}$ oxidation and at least 0.14 mol $\mathrm{NaNO}_{2}$ (or $50 \mathrm{~mL}$ of $5.65 \mathrm{M} \mathrm{NaNO}_{2}$ ) for $\mathrm{MnO}_{2}$ dissolution. These quantities are sufficiently small that it may be appropriate to add them through a charge funnel rather than with short pump cycles (i.e., $36 \mathrm{~s}$ for $\mathrm{NaMnO}_{4}$ addition and $25 \mathrm{~s}$ for $\mathrm{NaNO}_{2}$ addition).

\subsection{Operational Improvements}

All testing has demonstrated that the end point can be determined through visual inspection of the filtrate solution. When brown $\mathrm{MnO}_{2}$ solids form and persist in solution, analyses have consistently shown that the $\mathrm{C}_{2} \mathrm{O}_{4}{ }^{2-}$ concentration is less than $100 \mathrm{mg} / \mathrm{L}$. During ramp-up operations, it is advised that HB-Line establish a basis for visual inspection by correlating visual inspections with IC anion analyses. This could be accomplished by interrupting the feeding of $\mathrm{NaMnO}_{4}$ at approximately $75 \%$ of the recommended amount (chosen arbitrarily), collecting a sample, noting its visual characteristics for brown solids, completing the recommended feed amount and, if brown solids are present, withdrawing another sample. Analyze both samples by IC anion to demonstrate that the presence of brown solids corresponds to the absence of $\mathrm{H}_{2} \mathrm{C}_{2} \mathrm{O}_{4}$. If validated, for full-scale operations use visual observations to determine the reaction end point with occasional spot checks.

During ramp-up operations, it is also advisable for $\mathrm{NaNO}_{2}$ additions that HB-Line establish a basis for visual inspection by correlating them with ICPES analyses. This could be accomplished by interrupting the feeding of $\mathrm{NaNO}_{2}$ at approximately $90 \%$ of the recommended amount, collecting a sample, and noting its visual characteristics for brown solids. If the sample still contains solids, add $10 \%$ of the recommended amount and sample again. Repeat this cycle until the solution contains no visible $\mathrm{MnO}_{2}$ 
solids. When the sample is free of visible solids, retain the sample for analysis and complete $\mathrm{NaNO}_{2}$ addition by adding $25 \%$ of the recommended volume of $\mathrm{NaNO}_{2}$ solution. Collect a second sample and analyze both samples by ICPES. Both samples should analyze at the same Mn concentration but different Na concentrations. This will demonstrate that a solution visibly free of brown solids does not contain residual $\mathrm{MnO}_{2}$. Once validated, full-scale operations would be able to use visual observations to determine that the $\mathrm{NaNO}_{2}$ addition end point has been achieved. Because there are no Pu-bearing solids in the samples, continued sampling and analyses beyond this process validation step could be omitted.

\subsection{References}

1. R. H. Smith and P. H. Werling, "HB-Line Pu-239 Flow Sheet (U)", NMS-EHB-2000-00045 R2, October 2001.

2. S. L. Garrison, "HB-Line Flowsheet for Production of Plutonium Oxide in Phase II", "SRNS-F31002012-0011 R1, February 2013.

3. S. B. Beck, "Insure Previous Pu Campaign Permanganate Reaction Kinetics Are Valid for Current HB-Line Waste Minimization Strategy”, Technical Task Request NMMD-HTS-2014-3292, February 2014.

4. C. A. Nash, R. A. Pierce, and M. L. Crowder, "Task Technical and Quality Assurance Plan for HB Line Permanganate-Oxalate Reaction Kinetics”, SRNL-RP-2014-00230, March 2014.

5. B. C. Hill and M. G. Bronikowski, "Gas Generation during Sodium Permanganate Addition to HBLine Phase II Filtrate Tank (U)”, WSRC-TR-2002-00350, August 2002.

6. J. H. Gray, "The Formation and Dissolution of Plutonium Oxalate Solids in HB-Line Phase II Filtrate Streams”, WSRC-TR-2001-00317, July 2001.

7. R. S. McBride, "The Standardization of Potassium Permanganate Solution by Sodium Oxalate”, Bulletin of the Bureau of Standards, Vol. 8, 611-642, 1913.

8. N. Nelson, "Mediated Electrochemical Oxidation of Mixed Wastes", Hazardous and Radioactive Waste Treatment Technologies Handbook, Section 5.2.3, CRC Press, 2001.

9. O. J. Wick (ed), Plutonium Handbook, A Guide to the Technology, Volumes 1 and 2, Section 13-1, American Nuclear Society, 1980.

10. CRC Handbook of Chemistry and Physics, $94^{\text {th }}$ Edition, Internet Version, 5-80, 2014. 


\subsection{APPENDIX}

9.1 Gas-Volume Collection Data from Process Flowsheet Tests

\begin{tabular}{|c|c|c|c|c|c|c|c|c|c|c|c|}
\hline & P1 & P2 & P3 & P6 & P7 & P8 & P9 & P4 & P4 & P5 & P5 \\
\hline Pump & Cylinder & Cylinder & Cylinder & Cylinder & Cylinder & Cylinder & Cylinder & Pump & Cylinder & Pump & Cylinder \\
\hline Time & Volume & Volume & Volume & Volume & Volume & Volume & Volume & Time & Volume & Time & Volume \\
\hline$(\mathrm{min})$ & $(\mathrm{mL})$ & $(\mathrm{mL})$ & $(\mathrm{mL})$ & $(\mathrm{mL})$ & $\underline{(\mathrm{mL})}$ & $(\mathrm{mL})$ & $(\mathrm{mL})$ & (mm:ss) & $(\mathrm{mL})$ & (mm:ss) & $\underline{(\mathrm{mL})}$ \\
\hline 0.00 & 25 & 25 & 40 & 30 & 33 & 25 & 25 & 0.00 & 45 & 0.00 & 34 \\
\hline 0.25 & 25 & 25 & 40 & 30 & 33 & 25 & 25 & 0.75 & 45 & 0.50 & 34 \\
\hline 0.50 & 25 & 25 & 40 & 30 & 33 & 25 & 25 & 1.50 & 45 & 1.00 & 34 \\
\hline 0.75 & 25 & 25 & 40 & 30 & 33 & 25 & 25 & 2.25 & 45 & 1.50 & 34 \\
\hline 1.00 & 25 & 25 & 40 & 30 & 33 & 25 & 25 & 3.00 & 50 & 2.00 & 36 \\
\hline 1.25 & 25 & 25 & 40 & 30 & 35 & 25 & 25 & 3.75 & 53 & 2.50 & 38 \\
\hline 1.50 & 25 & 25 & 40 & 30 & 38 & 27 & 25 & 4.50 & 58 & 3.00 & 41 \\
\hline 1.75 & 30 & 25 & 42 & 30 & 40 & 29 & 25 & 5.25 & 65 & 3.50 & 44 \\
\hline 2.00 & 35 & 25 & 44 & 32 & 43 & 30 & 25 & 6.00 & 70 & 4.00 & 48 \\
\hline 2.25 & 40 & 25 & 46 & 35 & 46 & 31 & 25 & 6.75 & 80 & 4.50 & 55 \\
\hline 2.50 & 45 & 30 & 48 & 37 & 50 & 33 & 28 & 7.50 & 90 & 5.00 & 62 \\
\hline 2.75 & 50 & 32 & 50 & 39 & 55 & 35 & 30 & 8.25 & 100 & 5.50 & 70 \\
\hline 3.00 & 60 & 34 & 55 & 42 & 60 & 38 & 32 & 9.00 & 110 & 6.00 & 78 \\
\hline 3.25 & 70 & 37 & 60 & 45 & 65 & 40 & 35 & 9.75 & 123 & 6.50 & 87 \\
\hline 3.50 & 80 & 40 & 65 & 50 & 72 & 45 & 38 & 10.50 & 135 & 7.00 & 97 \\
\hline 3.75 & 90 & 45 & 70 & 55 & 80 & 50 & 41 & 11.25 & 150 & 7.50 & 110 \\
\hline 4.00 & 105 & 55 & 75 & 65 & 90 & 55 & 45 & 12.00 & 165 & 8.00 & 120 \\
\hline 4.25 & 120 & 65 & 82 & 80 & 98 & 62 & 50 & 12.75 & 182 & 8.50 & 130 \\
\hline 4.50 & 135 & 75 & 90 & 90 & 105 & 70 & 55 & 13.50 & 200 & 9.00 & 140 \\
\hline 4.75 & 150 & 90 & 100 & 100 & 115 & 78 & 60 & 14.25 & 217 & 9.50 & 147 \\
\hline 5.00 & 165 & 100 & 110 & 115 & 130 & 85 & 65 & 15.00 & 235 & 10.00 & 155 \\
\hline 5.25 & 180 & 115 & 120 & 130 & 145 & 95 & 72 & 15.75 & 252 & 10.50 & 163 \\
\hline 5.50 & 195 & 130 & 130 & 150 & 160 & 105 & 80 & 16.50 & 270 & 11.00 & 170 \\
\hline 5.75 & 215 & 150 & 140 & 165 & 175 & 115 & 88 & 17.25 & 287 & 11.50 & 177 \\
\hline 6.00 & 230 & 165 & 152 & 185 & 192 & 125 & 95 & 18.00 & 305 & 12.00 & 185 \\
\hline 6.25 & 250 & 180 & 168 & 200 & 210 & 140 & 105 & 18.75 & 322 & 12.50 & 192 \\
\hline 6.50 & 270 & 200 & 185 & 220 & 225 & 155 & 115 & 19.50 & 342 & 13.00 & 198 \\
\hline 6.75 & 290 & 215 & 200 & 235 & 245 & 170 & 125 & 20.25 & 360 & 13.50 & 205 \\
\hline 7.00 & 310 & 235 & 215 & 250 & 265 & 180 & 135 & 21.00 & 377 & 14.00 & 212 \\
\hline 7.25 & 330 & 255 & 230 & 270 & 280 & 195 & 145 & 21.75 & 395 & 14.50 & 218 \\
\hline 7.50 & 350 & 270 & 245 & 290 & 300 & 210 & 155 & 22.50 & 403 & 15.00 & 227 \\
\hline 7.75 & 370 & 290 & 265 & 305 & 317 & 225 & 165 & 23.25 & 414 & 15.50 & 235 \\
\hline 8.00 & 390 & 310 & 285 & 325 & 335 & 240 & 175 & 24.00 & 425 & 16.00 & 245 \\
\hline 8.25 & 410 & 330 & 300 & 345 & 355 & 255 & 188 & 24.75 & 438 & 16.50 & 252 \\
\hline 8.50 & 430 & 350 & 320 & 365 & 375 & 275 & 200 & 25.50 & 450 & 17.00 & 259 \\
\hline 8.75 & 450 & 370 & 340 & 385 & 395 & 290 & 215 & 26.25 & 460 & 17.50 & 267 \\
\hline 9.00 & 465 & 390 & 360 & 395 & 410 & 310 & 228 & 27.00 & 470 & 18.00 & 276 \\
\hline 9.25 & 485 & 410 & 380 & 410 & 427 & 325 & 240 & 27.75 & 480 & 18.50 & 285 \\
\hline 9.50 & 505 & 430 & 400 & 420 & 450 & 345 & 253 & 28.50 & 498 & 19.00 & 295 \\
\hline 9.75 & 520 & 450 & 420 & 435 & 462 & 360 & 266 & 29.25 & 515 & 19.50 & 305 \\
\hline 10.00 & 535 & 465 & 440 & 455 & 475 & 380 & 280 & 30.00 & 530 & 20.00 & 315 \\
\hline 10.25 & 550 & 480 & 460 & 465 & 485 & 400 & 295 & 30.75 & 535 & 20.50 & 325 \\
\hline 10.50 & 565 & 495 & 475 & 475 & 495 & 420 & 310 & 31.50 & 547 & 21.00 & 335 \\
\hline 10.75 & 575 & 505 & 490 & 485 & & 440 & 325 & & & 21.50 & 347 \\
\hline 11.00 & 585 & 520 & 505 & 500 & & 455 & 340 & & & 22.00 & 358 \\
\hline 11.25 & 595 & 530 & 515 & 505 & & 468 & 355 & & & 22.50 & 370 \\
\hline 11.50 & 600 & 540 & 525 & 510 & & 480 & 370 & & & 23.00 & 380 \\
\hline 11.75 & 605 & 550 & 538 & 515 & & 495 & 388 & & & 23.50 & 390 \\
\hline 12.00 & 612 & 555 & 550 & 520 & & 505 & 400 & & & 24.00 & 402 \\
\hline 12.25 & 620 & 560 & 558 & 520 & & 515 & 415 & & & 24.50 & 415 \\
\hline 12.50 & 625 & 565 & 565 & 525 & & 525 & 430 & & & 25.00 & 427 \\
\hline 12.75 & 630 & 570 & 570 & 530 & & 535 & 450 & & & 25.50 & 440 \\
\hline 13.00 & 635 & 577 & 575 & 535 & & 545 & 465 & & & 26.00 & 452 \\
\hline 13.25 & 640 & 585 & 582 & 540 & & 550 & 480 & & & 26.50 & 465 \\
\hline 13.50 & 645 & 590 & 590 & 545 & & 560 & 495 & & & 27.00 & 475 \\
\hline 13.75 & 650 & 595 & 595 & 450 & & 570 & 510 & & & 27.50 & 487 \\
\hline 14.00 & & 600 & 600 & 548 & & 575 & 525 & & & 28.00 & 500 \\
\hline 15.00 & & 613 & 618 & 560 & & 590 & 595 & & & 28.50 & 512 \\
\hline 16.00 & & 625 & 630 & 570 & & 603 & 625 & & & 29.00 & 525 \\
\hline 17.00 & & 638 & 640 & 575 & & 615 & 650 & & & 29.50 & 540 \\
\hline 18.00 & & 642 & 647 & 580 & & 620 & 665 & & & 30.00 & 552 \\
\hline 19.00 & & 646 & 652 & 585 & & 628 & 675 & & & 30.50 & 565 \\
\hline 20.00 & & 650 & 658 & 590 & & 635 & 682 & & & 31.00 & 575 \\
\hline 21.00 & & & & & & & 688 & & & 32.00 & 590 \\
\hline 22.00 & & & & & & & 691 & & & 33.00 & 599 \\
\hline \multirow[t]{4}{*}{ END } & & 665 & 675 & 600 & & 655 & 700 & & & 34.00 & 606 \\
\hline & & & & & & & & & & 35.00 & 613 \\
\hline & & & & & & & & & & 36.00 & 617 \\
\hline & & & & & & & & & & END & 625 \\
\hline
\end{tabular}




\section{Distribution:}

S. L. Marra, 773-A

T. B. Brown, 773-A

D. H. McGuire, 999-W

S. D. Fink, 773-A

C. C. Herman, 773-A

E. N. Hoffman, 999-W

F. M. Pennebaker, 773-42A

W. R. Wilmarth, 773-A

R. A. Pierce, 773-A

T. C. Shehee, 773-A

C. A. Nash, 773-A

M. L. Crowder, 773-A

P. R. Jackson, 703-46A

Records Administration (EDWS)
S. L. Garrison, 704-2H

P. B. Andrews, 704-2H

K. P. Burrows, 704-2H

S. L. Hudlow, 221-H

A. E. Kelly, 221-H

J. L. Bodkin, 221-H

K. J. Usher, 704-2H

J. B. Schaade, 704-2H

M. J. Lewczyk, 221-H

K. J. Gallahue, 221-H

J. E. Therrell, 704-2H

J. M. Jordan, 704-2H

K. D. Scaggs, 704-2H

T. E. Worth, 221-H

A. T. Masterson, 704-2H

A. B. Hickman, 704-2H

C. E. Johnson, 704-2H

J. Mancilla, 704-2H

M. T. Pelc, 704-2H

J. L. Varble, 704-2H

R. M. Mobley, 704-2H 